\title{
A spinner-integrated wind lidar for enhanced wind turbine control
}

Mikkelsen, Torben; Angelou, Nikolas; Hansen, Kasper Hjorth; Sjöholm, Mikael; Harris, M.; Slinger, C.; Hadley, P.; Scullion, R.; Ellis, G.; Vives, G.

Published in:
Wind Energy

Link to article, DOI:

10.1002/we.1564

Publication date:

2013

Document Version

Publisher's PDF, also known as Version of record

Link back to DTU Orbit

Citation (APA):

Mikkelsen, T., Angelou, N., Hansen, K. H., Sjöholm, M., Harris, M., Slinger, C., Hadley, P., Scullion, R., Ellis, G., \& Vives, G. (2013). A spinner-integrated wind lidar for enhanced wind turbine control. Wind Energy, 16, 625-643. https://doi.org/10.1002/we.1564

\section{General rights}

Copyright and moral rights for the publications made accessible in the public portal are retained by the authors and/or other copyright owners and it is a condition of accessing publications that users recognise and abide by the legal requirements associated with these rights.

- Users may download and print one copy of any publication from the public portal for the purpose of private study or research.

- You may not further distribute the material or use it for any profit-making activity or commercial gain

- You may freely distribute the URL identifying the publication in the public portal 


\title{
A spinner-integrated wind lidar for enhanced wind turbine control
}

\author{
T. Mikkelsen ${ }^{1}$, N. Angelou ${ }^{1}$, K. Hansen ${ }^{1}$, M. Sjöholm ${ }^{1}$, M. Harris ${ }^{2}$, C. Slinger ${ }^{2}$, P. Hadley ${ }^{2}$, \\ R. Scullion ${ }^{2}$, G. Ellis ${ }^{2}$ and G. Vives ${ }^{2}$ \\ 1 Department of Wind Energy, Technical University of Denmark, DTU Risø Campus, Frederiksborgvej 399, 4000 Roskilde, Denmark \\ 2 ZephIR Ltd., Natural Power, The Old Barns, Fairoaks Farm, Hollybush, Ledbury HR8 1EU, UK
}

\begin{abstract}
A field test with a continuous wave wind lidar (ZephIR) installed in the rotating spinner of a wind turbine for unimpeded preview measurements of the upwind approaching wind conditions is described. The experimental setup with the wind lidar on the tip of the rotating spinner of a large $80 \mathrm{~m}$ rotor diameter, $59 \mathrm{~m}$ hub height $2.3 \mathrm{MW}$ wind turbine (Vestas NM80), located at Tjæreborg Enge in western Denmark is presented. Preview wind data at two selected upwind measurement distances, acquired during two measurement periods of different wind speed and atmospheric stability conditions, are analyzed. The lidar-measured speed, shear and direction of the wind field previewed in front of the turbine are compared with reference measurements from an adjacent met mast and also with the speed and direction measurements on top of the nacelle behind the rotor plane used by the wind turbine itself. Yaw alignment of the wind turbine based on the spinner lidar measurements is compared with wind direction measurements from both the nearby reference met mast and the turbine's own yaw alignment wind vane. Furthermore, the ability to detect vertical wind shear and vertical direction veer in the inflow, through the analysis of the spinner lidar data, is investigated. Finally, the potential for enhancing turbine control and performance based on wind lidar preview measurements in combination with feed-forward enabled turbine controllers is discussed. Copyright (C) 2012 John Wiley \& Sons, Ltd.
\end{abstract}

\section{KEYWORDS}

wind lidar; laser-based anemometer; coherent Doppler lidar; preview; prevision-based control; feed-forward control; wind turbine sensor integration; yaw and pitch control; power curve measurements; upwind inflow monitoring

\section{Correspondence}

T. Mikkelsen, Department of Wind Energy, Technical University of Denmark, DTU Risø Campus, Frederiksborgvej 399,4000 Roskilde, Denmark.

E-mail: tomi@dtu.dk

Received 15 January 2011; Revised 14 September 2012; Accepted 18 September 2012

\section{INTRODUCTION}

Remote sensing-based wind measurement technology, called wind lidar, short for light detection and ranging, has been around since the early 1970s and is similar to radar in the sense that it relies on the transmission of electromagnetic energy and then analyzes the return that bounces back to determine information about the atmospheric objects from which the electromagnetic energy or waves scatter. For example, the speed of a scattering object can be found from detecting the change in the backscattered wave's frequency (the well-known Doppler effect). The key difference, however, between lidar and radar is the transmitted wavelength and the size of the scattering objects. The lidar used here has light waves that are only micrometers $(1.55 \mu \mathrm{m})$ in wavelength. At this wavelength, radiation in the atmosphere is mainly Mie scattered and hence Doppler shifted by many tiny, micrometer small in size, naturally occurring aerosols and particles in the atmospheric boundary layer such as dust, water droplets, pollution, pollen and salt crystals that are suspended and drifting along at the speed of the wind.

\subsection{Lidar potential for load reduction and increased power production}

The advances in optical fiber technology and telecom component-based wind lidar remote sensing ${ }^{1-7}$ have recently spurred renewed interest for improving wind energy cost-effectiveness through wind turbine-integrated lidar systems, providing upwind prevision of incoming wind fields in combination with advanced feed-forward control. 
Since the introduction of the first commercial all-fiber lidar (ZephIR, Ledbury, UK) in 2003/2004, this new technological approach to wind remote sensing is today radically improving the cost-effectiveness, the reliability and the overall utility of lidar systems. It has application for wind resource assessment, measurement of local wind conditions and, as discussed in this paper, also for wind turbine control. The lidar-integrated preview technique provides today a genuine prospect for improvement of future turbine design and performance..$^{8-17}$

With respect to full-scale megawatt turbine field testing with lidars for control, a first field test addressing wind lidar-based control capability was implemented in an experiment in 2003, where a turbine hub-mounted lidar, a prototype ZephIR lidar, was placed on top of the nacelle behind the rotor on a Nordex $\mathrm{N} 90$ turbine (Postlow, $5 \mathrm{~km} \mathrm{~W}$ of Anklam, N. E. German). ${ }^{4}$ The lidar stared through the blades of the turbine and demonstrated the feasibility of accurate wind speed measurements at ranges up to $200 \mathrm{~m}$ in front of the turbine blades. Several investigations, most of which are simulation based, have subsequently addressed the potential for enhanced wind turbine control based on lidar preview with the aim to investigate the potential for load reductions, both for fatigue and for extreme loads, and the potential for increased energy capture:

i. A nacelle-based lidar system that provided preview information of the wind inflow in front of wind turbines was investigated by Schlipf et ll $^{8}$ with respect to the potential for improved feed-forward speed regulation via a look-ahead update of a collective pitch control. Performance of the controller was evaluated through simulations with and without a feed-forward controller. For a case with a deterministic gust, reductions in standard deviation of $91 \%, 90 \%$ and $71 \%$ were predicted for rotor speed, aerodynamic moment and tower fore-aft, respectively. In case of turbulence, reductions of $77 \%, 32 \%$ and $17 \%$ were predicted. Another simulation indicated that lidar-assisted collective pitch control load reduction was best obtained at high turbulence and high wind speeds in combination with a look-ahead feed-forward controller. ${ }^{9}$

ii. For a conically scanning continuous wave (CW) lidar installed in a horizontal-axis wind turbine, similar to the spinner lidar installation described subsequently, simulation of lidar-based yaw alignment in turbulent flow shows that lidar-assisted yaw alignment is anticipated to be achievable with a precision of a few degrees, even in highly turbulent flow. ${ }^{10}$

iii. Also a combined feedback/feed-forward blade pitch control has been simulated and compared with industry-standard baseline controllers during operation in realistic turbulent winds. Three different feed-forward controllers designed to reduce fatigue loads and increasing turbine lifetime have been investigated on the basis of simulated lidar measurements of the incoming wind fields. ${ }^{11}$

iv. A time-varying model predictive controller has been developed that uses preview measurements of wind speeds approaching the turbine. Its performance has been evaluated using ideal, undistorted measurements at positions that rotate with the turbine blade as a reference and simulated measurements obtained at the same locations including distortion characteristic of a preview lidar system. ${ }^{12}$

v. A feed-forward controller has been proposed and simulated in standard operating conditions using two different measurement methodologies: local measurements of angle of attack in combination with relative velocity at a radial position on each blade and upwind inflow measurements from a spinner-mounted lidar. For both cases, the feed-forward controller was able to remove the 1P frequency peak in the load spectrum. Fatigue load could be reduced by approximately $30 \%$ on the basis of simulated local inflow measurements and by approximately $20 \%$ for the case of the simulated prevision spinner lidar measurements. ${ }^{13}$

vi. Another study focused on wind turbine-integrated upwind-looking lidars' potential for improving the turbine's yaw alignment compared with traditional devices, such as hub-mounted wind vanes and sonic anemometers. The original yaw alignment system of an operating turbine was synthesized by analyzing available data from a turbine and an adjacent meteorological mast. In absence of a preview lidar, unobstructed yaw alignment control wind direction data were measured in a nearby met tower at hub height. With a simulated correction scheme, the yield at below rated power could be raised $1-5 \% .^{14}$

vii. A simulation study investigated the potential for improving yaw alignment using upwind inflow measurements from a spinner lidar with three different upwind scan configurations: linear horizontal scanning, circular scanning and a 2D cone filling scan pattern. ${ }^{15}$ Lidar-based yaw control using the circular scanning method was in addition evaluated against a met tower reference measurement of wind direction during some of the field tests described further on in this paper. ${ }^{16}$ When the circularly scanned inflow by the spinner lidar was allowed to align the turbine into the winds, the turbines' yaw misalignment could be contained within a $4^{\circ}$ error interval over a $2 \mathrm{~h}$ measurement period, even during periods of high level of turbulence.

viii. The potential for the yearly energy production of a $5 \mathrm{MW}$ turbine is estimated to be enhanced by a couple of per cent if the turbine is steered into the wind by lidar-based yaw control over traditional nacelle-based sonic anemometer control. ${ }^{17}$

The aforementioned referenced works and investigations address enhanced turbine performance that is potentially achievable by combining accurate and undisturbed upwind-previewed inflow measurements as real-time input signals to 
advanced feedback/feed-forward controllers. In several cases, the referenced investigations that are all based on simulations have predicted a significant potential for load reduction with lidar-based feed-forward control, and in some cases power gains, although minor, have been predicted as well.

Before, however, the potential benefits of lidar preview and more advanced feed-forward control algorithms become convincing and attractive for implementation, confidence must at first be acquired on the feasibility of the predicted load reductions.

Accurate wind profile measurements from a ground position can be obtained by commercially available wind lidars at all heights around a wind turbine, but a ground installation for wind turbine control is far from ideal. By sending up laser beams from below, effectively a geometric cone of air, with its apex at the base of the turbine and the opening of the cone angled outward, is probed. Ground-based remote sensing gives understanding of wind speeds aloft but little sense of how winds are changing in real-time as they approach the turbine. To capture this information, we propose that the wind lidar needs to take its measurements around the turbine's rotating axis, that is, about the line pointing upwind, from the center of the turbine rotor itself. In particular, specific advantages from installation of the upwind scanning lidar on the turbine's main axis include symmetrical measurements in the (upwind translated) rotor plane, co-yawing of the lidar's pointing direction along the turbine's main axis, projected wind speed more closely aligned with the lidar's line-of-sight than is the case for the corresponding ground-based installations and advantageous measurement over ground-based mode in particular for offshore environments.

In this paper, therefore, the main focus is on field testing and experimental achievements with wind turbine integrated wind lidars for control. We present experimental rotor plane upwind lidar measurements including data analysis and corresponding data interpretation from a field campaign in 2009 where the conically scanning lidar was installed in the spinner of a test wind turbine situated at Tjæreborg Enge near Esbjerg in Denmark.

The findings presented in this paper in particular concentrate on analysis of two distinct measurement periods, each with different atmospheric stability conditions: The first data set was acquired during a nighttime low turbulence measurement period whereas the second data set was obtained during a daytime period characterized by unstable and well-mixed boundary-layer turbulence.

The presented measurement time series therefore contribute two realistic wind field scenarios on the basis of lidar-previewed upwind inflow measurements. The two data sets, obtained in very different atmospheric stability conditions, can be used as reference and design test cases for performance testing of existing and new controllers, including, e.g. advanced wind turbine feed-forward controllers, for simulation of lidar preview turbine performance.

\section{EXPERIMENTAL SETUP}

A modified ZephIR wind lidar-in the following denoted 'spinner lidar' — was installed on the very tip of the rotating spinner of an NM80 2.3 MW test turbine (NEG Micon, Randers, Denmark) with $80 \mathrm{~m}$ rotor diameter situated less than $1 \mathrm{~km}$ from the coast in an onshore small wind turbine park at Tjæreborg Enge in Denmark. The spinner lidar was aligned coaxially with the main axis of the turbine ( $c f$. Figures 1 and 2), and during the spring and summer periods of 2009, it scanned the approaching wind field on concentric circles around the turbine axis at selected upwind distances in front of the rotor plane.

\subsection{Test turbine site and met mast}

The spinner lidar tests took place in the NM80 turbine marked by No. 2 in Figure 3. The two sectors representative of undisturbed inflow to the NM80 test turbine are indicated and marked by I (northeasterly inflow over land-undisturbed inflow from sector $10^{\circ}-45^{\circ}$ ) and II (west-southwesterly offshore inflow from sector $225^{\circ}-245^{\circ}$ ). A $93 \mathrm{~m}$ tall met mast was located at a distance of $310 \mathrm{~m}$ toward the WSW at bearings $233^{\circ}$ from the NM80 test turbine. The met mast was equipped with boom-mounted calibrated cup anemometers of type P2546 at heights 93, 77, 57, 41, 28.5 and $17 \mathrm{~m}$ and sonic anemometers at heights 93 and $57 \mathrm{~m}$. In addition, two $360^{\circ}$ resolver-based wind vanes were installed at heights 93 and $57 \mathrm{~m}$. The met mast wind vane and cup anemometer data were sampled at $10 \mathrm{~Hz}$ and the sonic anemometers at $20 \mathrm{~Hz}$. Mean values of the met mast's sensor measurements were obtainable at variable averaging time ranging in the interval between $1 \mathrm{~s}$ and $10 \mathrm{~min}$.

\subsection{The ZephIR wind lidar in the spinner of the turbine}

The experimental setup was designed for scanning cone half-angles of $15^{\circ}$ in the first data analysis period reported (nighttime stable atmospheric stratified inflow) and $30^{\circ}$ for the second (daytime unstable atmospheric stratified inflow) study case. During both measurement setups, the focus was adjusted to measure the approaching radial wind speeds in the rotor plane upwind near the two-third blade chord radius of the turbine blade, i.e. at the chord radius where maximum 


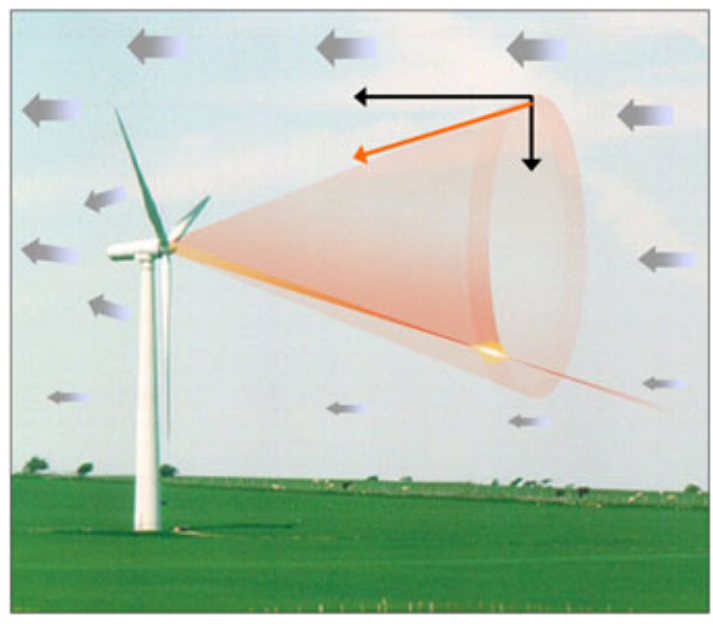

Figure 1. Concept of measuring the upwind inflow conditions from a lidar integrated in the tip of the rotating spinner. The red arrow represents the spinner lidar's line-of-sight projected measured upwind inflow.
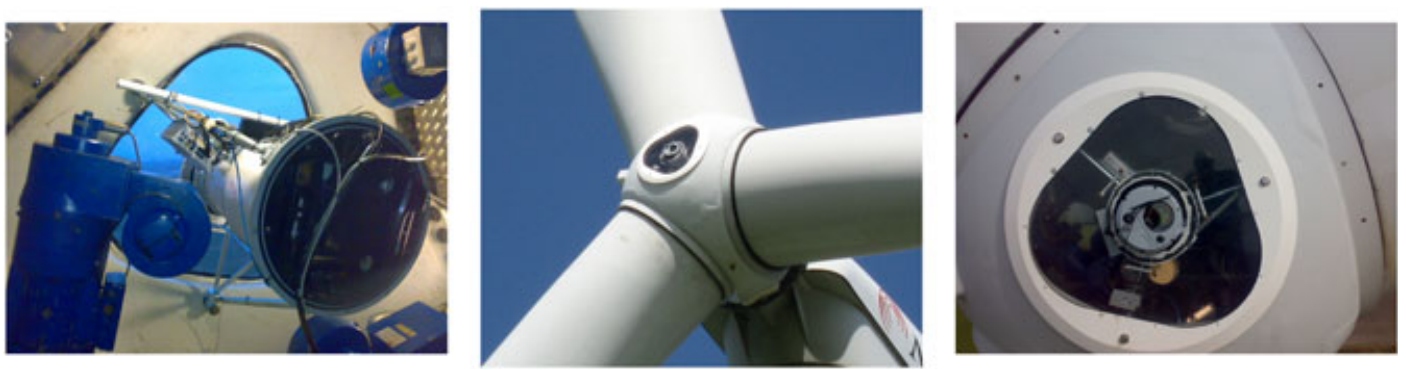

Figure 2. (Left) The upwind scanning spinner lidar installed on the turbine axis in the spinner tip of a $2.3 \mathrm{MW}$ NM80 test turbine, in between the turbines three (blue) pitch-control motors. (Middle) The spinner lidar measures the upwind approaching wind conditions by conical scanning the upwind inflow with a focused laser beam through a hole in the spinner-tip window. (Right) A close-up of the spinner lidar from outside.

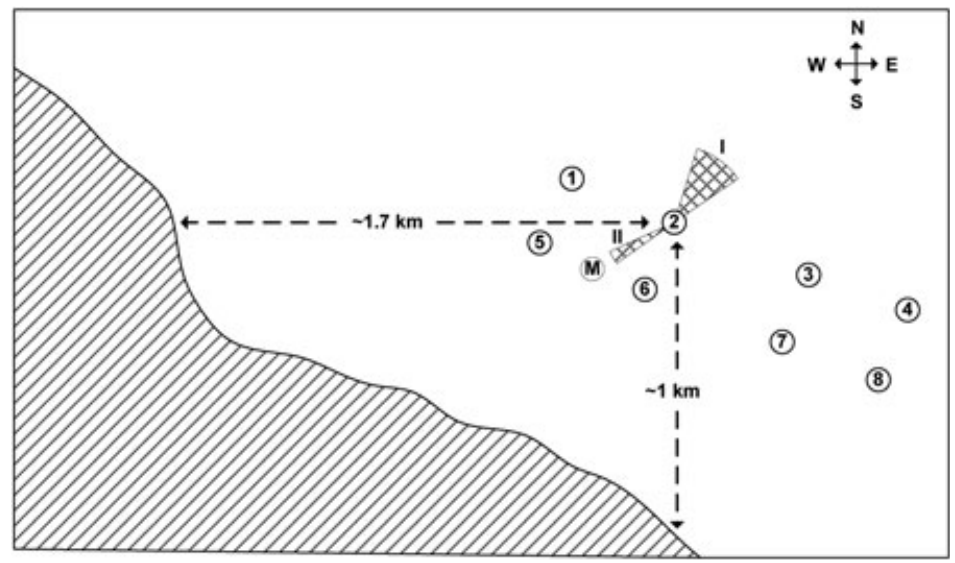

Figure 3. The test site at Tjæreborg Enge near Tjæreborg, Denmark where the spinner lidar experiments took place. The wind turbines situated in the small onshore wind farm are marked by numbers 1-8. The met mast providing reference and background wind and turbulence measurements data for the experiments is indicated by $\mathrm{M}$. 
power production on the blade is anticipated. The two-third chord radius corresponds to a radial distance along the laser beam to the focus point of 103 and $53 \mathrm{~m}$ for the $15^{\circ}$ and the $30^{\circ}$ scanning cones, respectively.

With the spinner lidar's focus distance set to $103 \mathrm{~m}$ in combination with the $15^{\circ}$ deflection angle, the wind speeds were measured at an upwind distance of $103 \mathrm{~m} \times \cos \left(15^{\circ}\right)=99.5 \mathrm{~m}$ corresponding to $99.5 / 80=1.24 \varnothing$ rotor diameter upwind, on a circle in a plane perpendicular to the turbine's main axis, which is tilted slightly upward $\left(5^{\circ}\right)$.

Although with focus distance set to $53 \mathrm{~m}$ in combination with the $30^{\circ}$ deflection angle, wind speeds were measured at an axial upwind distance of $53 \mathrm{~m} \times \cos \left(30^{\circ}\right)=45.9 \mathrm{~m}$, corresponding to $45.9 / 80=0.57 \varnothing$ rotor diameter upwind ( $c f$. Figure 4$)$.

\subsubsection{Lidar and scanner.}

The modified CW ZephIR wind lidar was equipped with a $1 \mathrm{~W}$ all fiber-based $1.575 \mu \mathrm{m}$ wavelength laser and operated such that it is eye safe and classified as Class 1 according to ISO-60825-1. An adjustable micro-precision focus motor moved the fiber that feeds laser radiation into a telescope. The telescope has a focal length of $200 \mathrm{~mm}$ and a $76.2 \mathrm{~mm}$ diameter aperture. A fiber-based circulator and a shot noise-limited photo detector are incorporated, such that in a natural aerosol-loaded atmospheric boundary layer, the lidar is able to detect signals equivalent to one photon for every $10^{12}$ photons transmitted. Using a built-in real-time spectral analysis module, the ZephIR wind lidar detects the small Doppler shifts of the backscattered laser radiation returned to the lidar from the sub-micron particles suspended in the air. These particles follow the atmospheric flow. The pointing direction of the focused beam and hence the probe volume were scanned in the rotor plane using a top-mounted, motor-driven, constant speed, rotating prism.

During operation, the spinner lidar measured 50 instantaneous radial wind speeds per second of the upwind circularscanned flow field. Each of these measurements represents the instantaneous projection of the wind velocity inside the focus-limited probe volume along the pointing direction of the laser beam. The radial wind speeds detected are derived from the mean Doppler shift of the backscattered radiation in the probe volume. ${ }^{1}$ Since the wind lidar diffraction limited probing volume is very narrow and elongated (i.e. pencil or needle shaped), the overall effective sounding range will be dominated by the radial intensity distribution of laser light in the pointing direction of the laser beam.

The spinner lidar telescope's probe length is determined by the telescope's focal range and its effective aperture. The probe length has been assessed both theoretically and experimentally to be about $26 \mathrm{~m}$ (full width half maximum of the laser light's intensity distribution around the focus range) at $103 \mathrm{~m}$ focal range (Experiment I—nighttime stable) and about $7 \mathrm{~m}$ at $53 \mathrm{~m}$ focal range (Experiment II-daytime unstable). ${ }^{5,6,19}$

Online real-time data access and remote lidar control were enabled via wireless telecommunication.

\subsubsection{Data analysis.}

The scan azimuth angle with respect to a fixed coordinate system (the ground) was calculated from recorded information from the spinner lidar's rotating optical wedge-shaped prism scanner relative to the spinner lidar in combination with measurements of the wind turbine's rotor position. With co-rotating prism and rotor, a full $360^{\circ}$ cone scan could be completed in about $0.8 \mathrm{~s}$ whereas radial wind speed Doppler spectra were streamed at a rate of $50 \mathrm{~Hz}$ to a PC installed adjacent to the spinner lidar.

Using the scan azimuth angle, the spinner lidar measurements of upwind inflow along the laser beam's instantaneous radial pointing direction were first projected along an axis parallel to the turbine's main shaft, then subsequently to an untilted and fixed coordinate system on the ground. These projections are briefly presented in Appendix A. A more detailed description of the wind lidar data coordinate transformations and analysis methodology is provided in Angelou et al. ${ }^{18}$

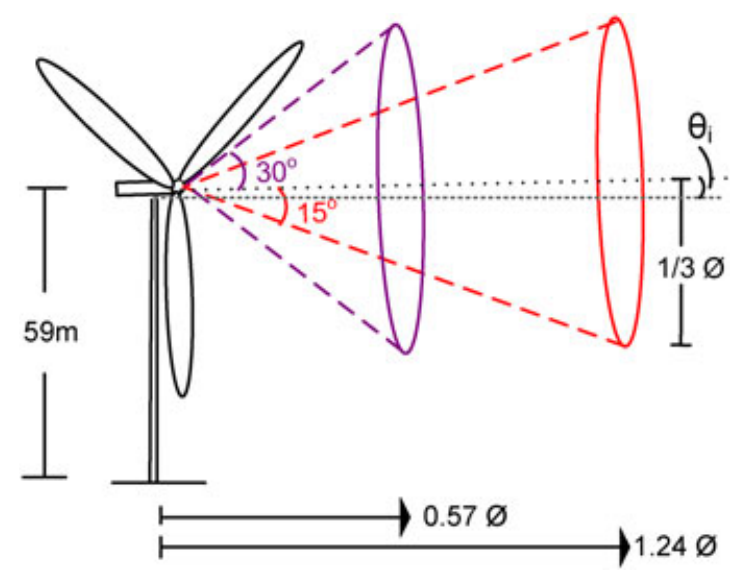

Figure 4. Geometry of the pre-view lidar measurements. The tilt angle of the turbine shaft axis is $\theta_{i}$. The turbine rotor diameter is $80 \mathrm{~m}$. The distance along the turbine axis to the scanned circles was 99.5 and $45.9 \mathrm{~m}$, in the cases of the $15^{\circ}$ and $30^{\circ}$ scan cones, respectively. 
Because the spinner lidar measures the sounding volume-averaged line-of-sight projections and not the full three-dimensional wind velocity vector, the estimations of the inflow axial wind speed $U$ and the turbine orientation (yaw) can show deviations resulting from differences between sounding volume-averaged and point measurements and also due to fluctuations in the two cross-wind components $(v, w)$ ever present in the inflow. The latter have become known as a lidar's 'Cyclops syndrome', that is, ambiguity associated with wind component retrieval based on a single line-of-sight projection of true three-dimensional wind vectors. A quantitative investigation of uncertainty of the combined sounding volume effects and associated 'Cyclops syndrome' errors for the particular spinner lidar configuration under study has been presented recently on the basis of a simulation study by Simley et $a .^{10}$

\section{PREVISION OF THE WIND TURBINE INFLOW}

Rotor plane upwind spinner lidar inflow measurements from two distinct measurement periods, one during a nighttime stable stratified inflow and another during daytime unstable stratified inflow, have been analyzed in detail and are presented in this section.

In the first measurement period, the inflow to the turbine was measured at $99.5 \mathrm{~m}(1.24 \varnothing)$ distance upwind with a $15^{\circ}$ deflection angle prism. Whereas in the second measurement period the inflow was measured at $45.9 \mathrm{~m}(0.57 \varnothing)$ upwind with a $30^{\circ}$ deflection angle prism in front of the turbine ( $c f$. Figure 4$)$.

\subsection{Upwind inflow measurements}

Figure 5 displays measured radial wind speeds in upwind inflow obtained by conical azimuth scanning of the spinner lidar around the turbine axis at a $1.24 \varnothing$ rotor diameter upwind distance, measured with the $15^{\circ}$ deflection angle prism during the night of 30 April 2009. Each of the four plots shows data from 10 full $360^{\circ}$ azimuth scans. According to data measured in
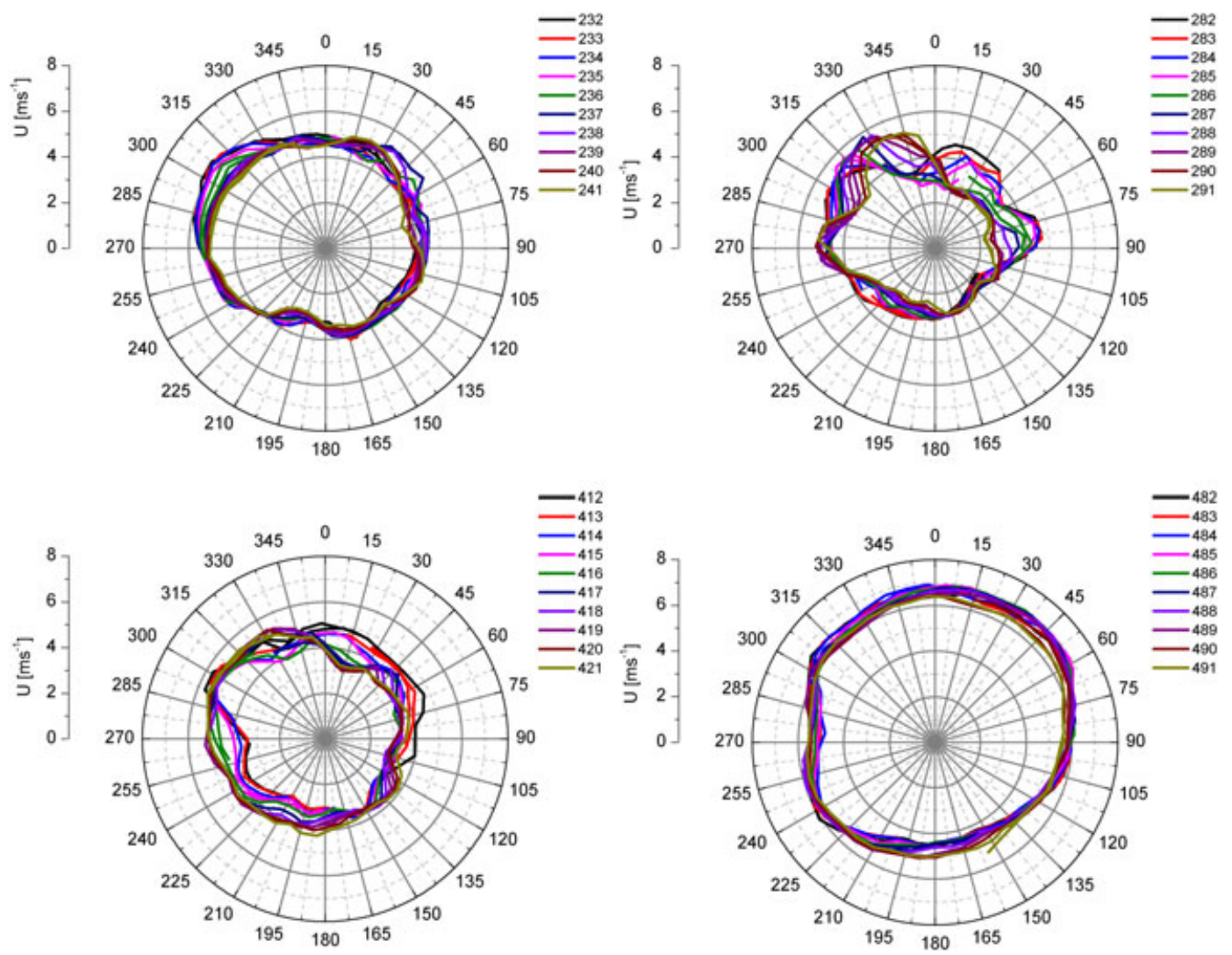

Figure 5. Four examples of spinner-lidar measured upstream radial wind speeds during the early morning on 30 April 2009 . Each of the four plots presents 10 consecutive $360^{\circ}$ scans; each containing about 400 measurement points over the rotor plane as retrieved during an $8 \mathrm{~s}$ sampling period, of the upwind inflow at $99.5 \mathrm{~m}(1.24 \varnothing)$ in front of the operating wind turbine. 
the adjacent met mast, the atmospheric boundary layer was strongly stratified and the turbulence was accordingly representative of stable stratified with sporadic outbursts of intermittent turbulence.

These, to our knowledge 'World first' upwind scanned inflow measurements from a rotating spinner show, not surprisingly, that the approaching wind field contains turbulent coherent structures, many of which have dimensions comparable with the rotor plane, and which can prevail in time over several seconds. Assuming that the standard 'Taylor's frozen turbulence' hypothesis applies, this indicates that coherent structures in the turbulence will impinge upon the rotating turbine blades a few seconds after they have been detected. ${ }^{20}$

The mean wind speed at hub height during the 30 April nighttime measurement period ranged between 5 and $8 \mathrm{~m} \mathrm{~s}^{-1}$, meaning that the measured turbulent structures should reach the turbine within a time span of $12-20 \mathrm{~s}$ later. Such lead times provide ample preview time for feed-forward pitch control of the blades to mitigate fatigue effects from strong wind shear. On the other hand, a too-long lead time may be insufficient for optimal pitch and speed control as turbulence structures will decay during transport to the rotor, depending on eddy size. ${ }^{20}$ Furthermore, a preview time of $10-20 \mathrm{~s}$ may well turn out to be too short for effective yaw control of a huge megawatt turbine for optimization of power production based on enhanced feed-forward yaw control. The optimal preview distance, taking into account decaying turbulence, is presently a research topic based on simulation at both European and US wind energy and turbine development research centers., 10,19-21

Figure 6 shows spinner-measured axial projected wind speeds measured in the rotor plane similar to the data in Figure 5 from the nighttime experiment in 30 April 2009. Here, however, all measured radial wind speeds sampled at $50 \mathrm{~Hz}$ over a full $10 \mathrm{~min}$ period are presented. The wind speed measurements represent a case where a strong vertical wind shear is present. The observed asymmetry in the wind speed measurements on the scan cone could be attributed to a wind veer (i.e. a variation of the wind direction with height), when taking into account the homogeneity of the landscape and the absence of wind turbine wakes. Wind shear is observed as the rotor plane projected wind speed in the topmost part of the scan, at $90 \mathrm{~m}$ above the ground and measures about $9 \mathrm{~m} \mathrm{~s}^{-1}$, whereas the wind speed in the bottom part of the scan, at $40 \mathrm{~m}$ above ground, is only about $6 \mathrm{~m} \mathrm{~s}^{-1}$. Wind veer is evident from the higher rotor plane projected wind speed at $\sim 330^{\circ}$, relative to the symmetric projected wind speed at the same height observed at $30^{\circ}$ azimuth, in an otherwise correctly yawed turbine (evident from the fact that the speed at $270^{\circ}$ equals the speed symmetrically measured at hub height at $90^{\circ}$ ).

It is furthermore evident from a visual inspection of the wind speed traces recorded in Figure 6 (left) that more turbulence is present in the lower part of the scans during the $10 \mathrm{~min}$ sampling period of this nighttime stable stratified inflow period. The standard deviation of the wind speed measurements closest to the ground $\left(180^{\circ}\right)$ is $0.35 \mathrm{~m} \mathrm{~s}^{-1}$, whereas at the top (at $\left.0^{\circ}\right)$, it is $0.14 \mathrm{~m} \mathrm{~s}^{-1}$. The measurements were acquired between 01:20 and 01:30.

In Figure 7, an example of a 10 min mean vertical wind profile measured by the turbine-integrated spinner lidar and the corresponding profile measured by the adjacent met mast is presented. The wind profiles are approximately linear with height indicative of a stable stratified mean wind flow. During the measurement period analyzed (between 01:00 and 03:40), the wind directions veered between north and $40^{\circ}$ east. With flow coming from $40^{\circ}$ east, the wake from the test turbines could possibly affect the met mast wind profile measurements ( $c f$. Figure 3 ).

In Figure 8, a $3 \mathrm{~h}$ long (01:00-03:40) time series of the spinner lidar-measured horizontal hub height wind speed is shown together with corresponding measurements from a cup anemometer in the met mast at $57 \mathrm{~m}$ (i.e. the cup anemometer closest to the hub height of $59 \mathrm{~m}$ ). The wind speed measurements are seen to correlate well, although it is evident that parts of the high-frequency fluctuations in the lidar wind measurement have been smoothened out because of the low-pass filter effect of the lidar's probing length along its line-of-sight. ${ }^{19-21}$ During the period between 02:40 and 03:15, corresponding to the interval between 6000 and $8000 \mathrm{~s}$ in Figure 8, the wind direction veered closer to and even beyond $40^{\circ}$ (see Figure 9).
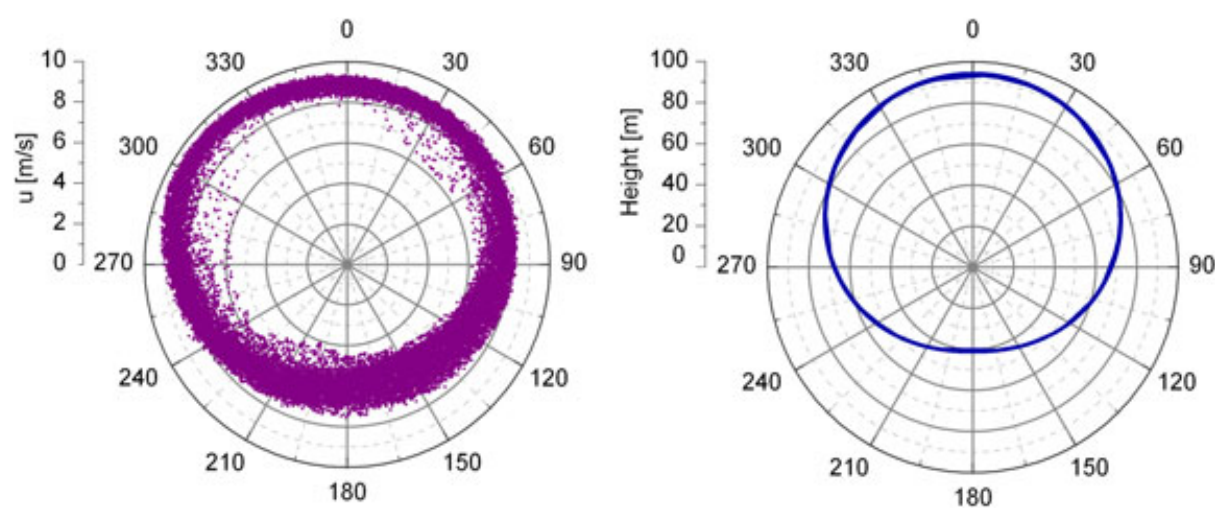

Figure 6. (Left) The spinner lidar's measured upwind wind speed sampled at $99.5 \mathrm{~m}$ during a 10 min period. (Right) The spinner lidar measurement loci relative to the ground are shown as a function of scan angle. 


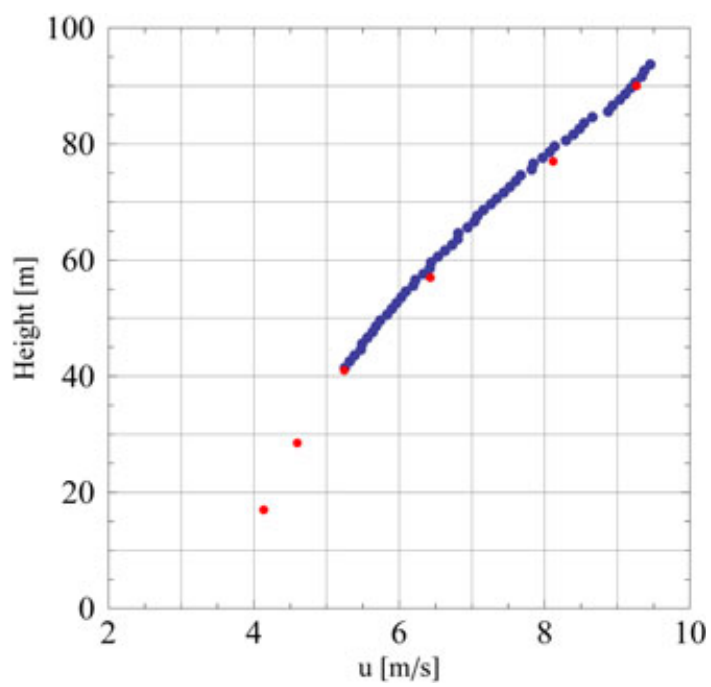

Figure 7. Example of a spinner lidar $10 \mathrm{~min}$ averaged vertical wind profile (blue dots) shown together with the corresponding mean wind speeds profile observed by the adjacent met mast (red dots) measured during stable stratified inflow at the night of 30 April (02:30).

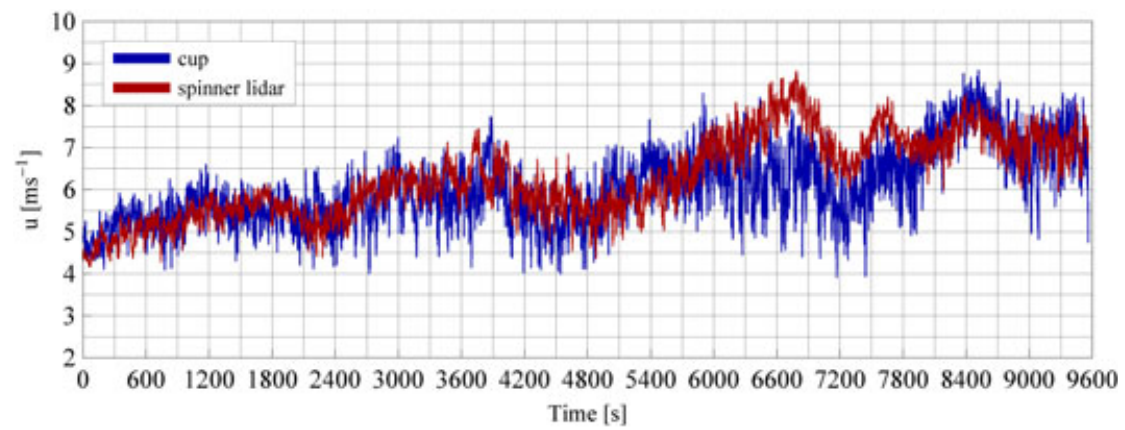

Figure 8. Spinner lidar measured wind speeds at hub height $(59 \mathrm{~m}$, red curve) shown together with wind speed measured by a met mast-mounted cup anemometer at $57 \mathrm{~m}$ (blue curve). The time series represent a $3 \mathrm{~h}$ data sampling period during the night of 30 April 2009 from 01:00 to 3:40.

With wind directions close to and above $40^{\circ}$, the wake from the NM80 test turbine could possibly affect the met mast located $310 \mathrm{~m}$ downstream in this flow direction and thereby also the cup anemometer measurements at $57 \mathrm{~m}$ height. This potential wake effect could possibly explain the wind speed difference observed between the spinner lidar and the met mast during this period.

\subsection{Measurements of the yaw alignment with the mean wind direction}

Standard operating wind turbines adjust yaw or 'heading' on the basis of nacelle-mounted wind measurement devices in combination with manufacture-specific controller-embedded yawing strategies. The purpose of yawing is to align the wind turbine's rotor plane perpendicular into the ever-changing wind directions of the ambient flow.

Different wind turbine manufacturers apply more or less conservative yawing alignment strategies, some of which are more focused on optimization of power production whereas others focus more on minimum wear of the yaw machinery, nacelle stability and loads during yaw.

Traditionally, the speed and direction of the ambient air flow are measured from a hub-mounted wind vane and anemometer installed on top of the nacelle behind the rotor plane. The wind turbine's control system then uses this information to control and run the yaw motors to adjust the heading of the wind turbine by turning (yawing) the nacelle.

During the 2009 Tjæreborg tests with the NM80 wind turbine, both the yaw angle and the nacelle-mounted wind vane and cup anemometer outputs were recorded. The wind turbine's geo-referenced pointing direction (absolute yaw direction) was recorded at $2 \mathrm{~Hz}$, logged from the control system of the wind turbine. The wind direction of the air flow was measured 


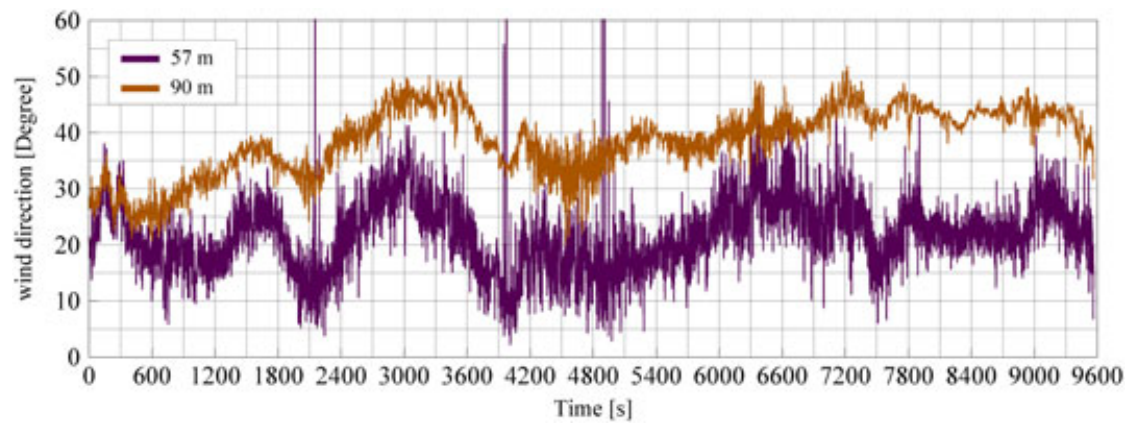

Figure 9. Wind direction veer observed during 30 April 2009 01:00-3:40 between the wind vanes in the met mast installed at 57 and $90 \mathrm{~m}$.

by three independent means: (1) from the spinner-mounted upwind-looking wind lidar data, (2) from the wind turbine's own built-in wind vane located on top of the nacelle behind the rotor plane and (3) from a standard calibrated wind vane mounted in the met mast at $57 \mathrm{~m}$ height.

The spinner lidar-measured horizontal yaw misalignment was calculated on the basis of two consecutive radial wind speed measurements from the lidar's conical scanning: one from near $90^{\circ}$ to the left in the cone (9 o'clock) and one from a subsequent speed measurement from a data point in the cone near $270^{\circ}$ to the right ( 3 o'clock). In this way, the almost instant yaw misalignment $\theta_{\mathrm{W}}$ could be determined once per full $360^{\circ}$ cone scan, that is, at an approximate data rate of $1 / 0.8 \mathrm{~s}^{-1}$ or $1.25 \mathrm{~Hz}$.

\subsubsection{Stable atmospheric conditions.}

The wind directions measured in the met mast and the yaw measurements gathered by the turbine itself during the stably stratified inflow of the 30 April period are shown in Figures 9 and 10.

The turbine's own embedded yawing strategy is seen to be conservative, since the test turbine only adjusts its yaw direction on a $10 \mathrm{~min}$ timescale, if the mean yaw error during the previous 10 min period exceeds $10^{\circ}$.

In Figure 11, an intercomparison of $30 \mathrm{~s}$ running-mean yaw misalignments is shown, which were observed during the $2 \mathrm{~h}$ and 40 min analysis period chosen from the night run of 30 April 2009. The misalignment of the wind turbine relative to the incoming wind direction was inferred with (1) the spinner lidar and (2) the nacelle-mounted wind vane. Although there is more scatter in the spinner lidar-based yaw misalignment measurements, the two wind direction time series are seen to correlate well. The correlation coefficient between the $30 \mathrm{~s}$ running-mean averaged direction measurements is 0.57 , whereas for a 10 min running mean average, it increased to 0.86 . Analysis of the cross-correlation between the two signals revealed that a maximum occurred with a time delay in the upwind lidar signal relative to the wind vane signal of about $\sim 12 \mathrm{~s}$. This corresponds well to the advection time for lidar measurements of the wind direction fluctuation at $99.5 \mathrm{~m}$ upwind distance with the observed mean wind speed in the range of $7-8 \mathrm{~m} \mathrm{~s}^{-1}$.

The excess jitter observed in the wind lidar-measured direction relative to the wind vane signal is, we believe, due to the line-of-sight 'Cyclops' projection uncertainty in combination with the applied methodology for the extraction of the upwind mean wind direction from only two spinner lidar radial wind speed measurements averaged over a $\pm 2.5 \mathrm{~m}$ vertical interval centered about hub height. The estimation of the wind direction becomes more stable and accurate as the cone angle increases. By using a narrow $15^{\circ}$ cone angle, the 'Cyclops' projection uncertainty due to ambiguity between wind direction and horizontal shear increases, which could explain the increased observed jitter.

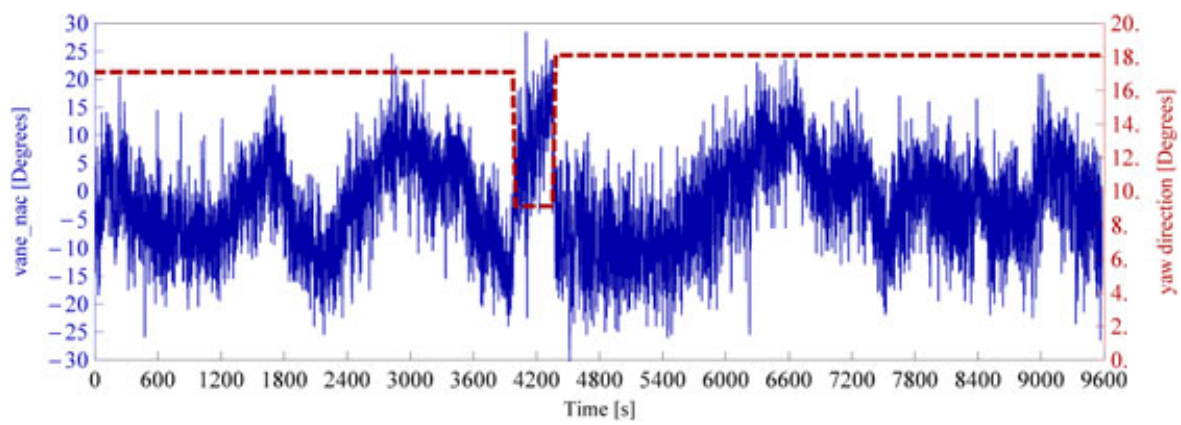

Figure 10. Ground-referenced yaw direction of the wind turbine (red curve) and corresponding instantaneous relative yaw misalignment (blue curve) measured by the wind turbine's nacelle wind vane. 


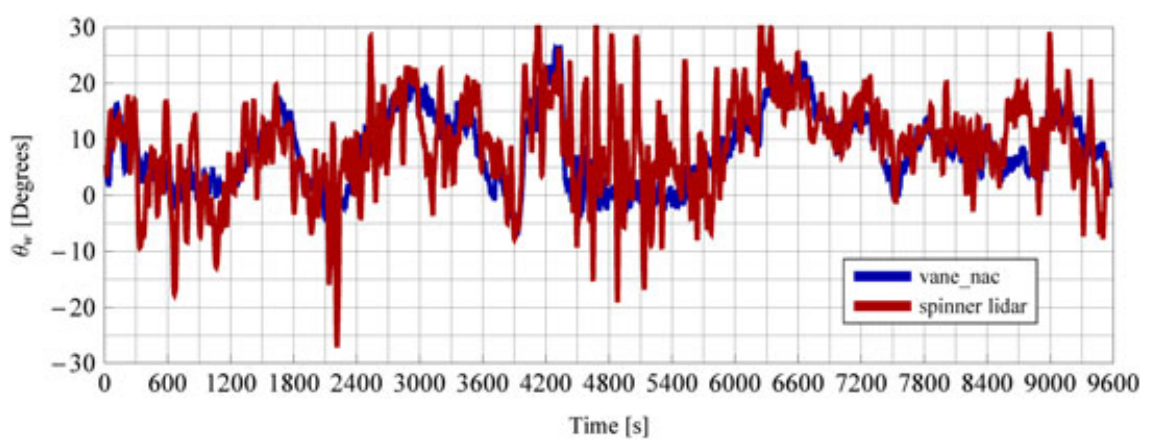

Figure 11. Observed relative wind direction yaw misalignments during a $2 \mathrm{~h} 40 \mathrm{~min}$ period during the night of 30 April 2009. Shown are measured yaw misalignment observed by the wind turbines own nacelle-mounted wind vane intercompared with the corresponding yaw misalignment inferred from the upwind looking spinner lidar measurements at $99.5 \mathrm{~m}$ upwind of the wind turbine (both graphs are presenting $30 \mathrm{~s}$ averages).

In Figure 12, yaw misalignment angles are shown as in Figure 11, but for spinner lidar-measured mean wind direction yaw misalignment filtered with six different running averaging times. In addition to the $30 \mathrm{~s}$ averaging time, the spinner lidar-measured yaw misalignment is shown for five additional different running-mean averaging times, increasing from 1 to $10 \mathrm{~min}$ ( $c f$. the legend in Figure 12). The scatter in the spinner lidar measured misalignment is, as anticipated, observed to diminish with increasing averaging time.

Table I presents the measured root-mean-square (RMS) error misalignments of the turbine relative to the wind direction measured by (1) the spinner lidar, (2) the wind vane installed on the nacelle and (3) the $57 \mathrm{~m}$ ( $2 \mathrm{~m}$ below hub height) reference wind vane installed in the met mast for different running-mean averaging times. Both the spinner lidar and the nacelle vane detect RMS yaw misalignments about $3^{\circ}$ higher than the wind vane in the reference met mast. A diminishing RMS yaw error with increasing averaging time is observed as anticipated for all three measurement methodologies. However, the nacelle vane RMS yaw error might erroneously be higher than the met mast reference because of the enhanced turbulence experienced behind the rotor on top of the nacelle. Furthermore, the higher lidar yaw misalignment RMS may result from the two-point method used in this study.

In Figure 13, we intercompare the 10 min running average yaw misalignment of the NM80 wind turbine relative to the wind direction measured by (1) the spinner-integrated wind lidar, (2) the nacelle mounted wind vane and (3) the met mast-mounted wind vane at $2 \mathrm{~m}$ below hub height. It is observed that the three different methods reveal a wind turbine yaw misalignment of the order of $10^{\circ}$, even in the case of the $10 \mathrm{~min}$ long averaging times. From the three independent yaw misalignment measurement methods that all seem to largely agree, we can rule out that the measured rather high yaw misalignment is solely caused by

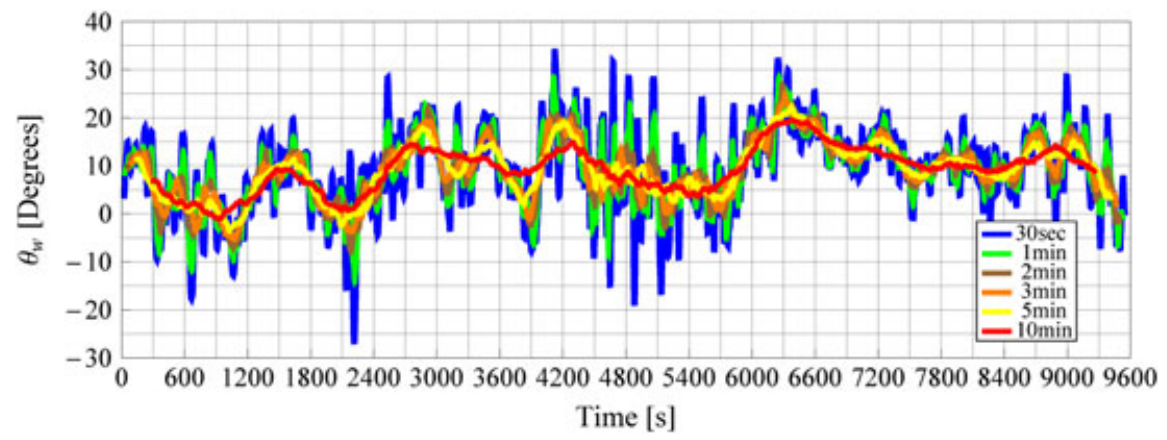

Figure 12. Yaw misalignment $\theta_{w}$ of the NM80 wind turbine relative to the spinner lidar measured wind direction in the rotor plane $103 \mathrm{~m}$ upwind with six different running-mean averaging applied (30 s, 1, 2, 3, 5 and $10 \mathrm{~min})$.

Table I. Measured RMS yaw misalignments (measured in degrees).

\begin{tabular}{|c|c|c|c|c|c|c|}
\hline Averaging time & $30 s$ & $1 \mathrm{~min}$ & $2 \min$ & $3 \min$ & $5 \min$ & $10 \mathrm{~min}$ \\
\hline Spinner lidar & 12.3 & 11.5 & 11.1 & 10.8 & 10.7 & 10.3 \\
\hline NM80 nacelle wind vane & 10.3 & 10.2 & 10.1 & 10.0 & 9.8 & 9.2 \\
\hline Met mast wind vane & 7.2 & 7.1 & 7.0 & 6.9 & 6.8 & 6.4 \\
\hline
\end{tabular}




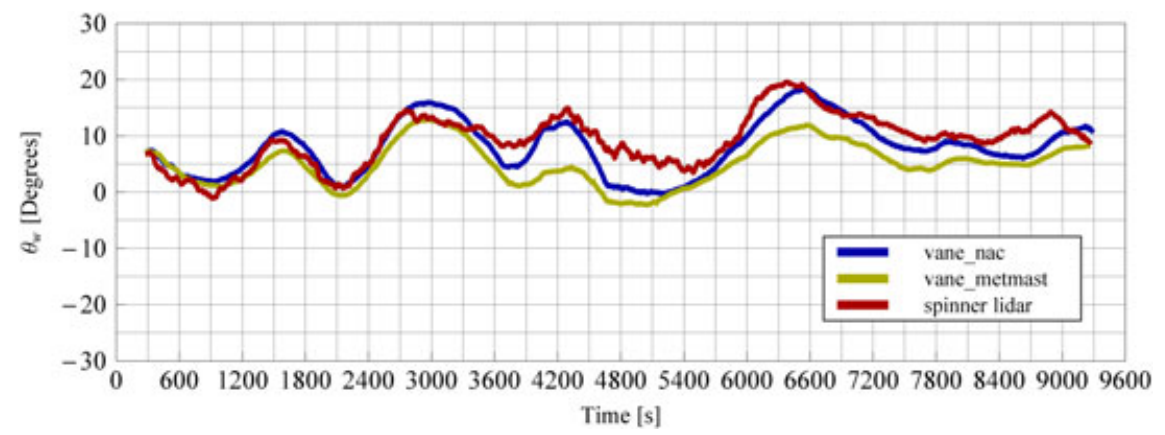

Figure 13. Yaw misalignment relative to the $10 \mathrm{~min}$ averaged mean wind direction measured by (1) the upwind-looking lidar, (2) the wind turbine's own nacelle-mounted wind vane behind the rotor and (3) the wind vane mounted $2 \mathrm{~m}$ below hub height in the met mast $310 \mathrm{~m}$ toward west-southwesterly.

erroneous wind direction measurements by the wind turbine's wind vane behind the rotor plane. Rather, it is believed that the observed relatively large yaw misalignment is a result of a conservative yaw alignment strategy embedded within the NM80 wind turbines yaw control algorithms.

\subsubsection{Unstable atmospheric conditions.}

The second period of 2009 Tjæreborg experiment data to be presented here originates from a period where the standard ZephIR's $30^{\circ}$ deflection angle optical scanning wedge prism was installed in the ZephIR spinner lidar. The focus distance was set to $53 \mathrm{~m}$, thus the spinner lidar was scanning in an approximately $45.9 \mathrm{~m}(0.57 \varnothing)$ upstream distance from the test turbine's rotor plane. Analysis of the attained measurements during the period from 12:30 to 13:10 on 16 July 2009 is presented here.

The wind turbine started operating approximately $100 \mathrm{~s}$ after 12:30. The external wind conditions provided wind speed in the range $6-7 \mathrm{~m} \mathrm{~s}^{-1}$ with the predominant wind direction from south west. The atmospheric stability was unstable with high levels of convective turbulence.

During this period, the wind direction varied between $220^{\circ}$ and $250^{\circ}$ measured at $57 \mathrm{~m}$ and between $240^{\circ}$ and $260^{\circ}$ at $90 \mathrm{~m}$ height ( $c f$. Figure 14). The turbine heading was observed to yaw between $238^{\circ}$ and $248^{\circ}$, following the clockwise drift of the wind direction ( $c f$. Figure 15).

This is a special data set because for the given wind direction, the inflow to the NM80 test turbine is channeled between two other wind turbines in the park (turbines 5 and 6 in Figure 3), then across the met mast before heading toward the NM80 test turbine with the spinner lidar installed. Consequently, it must be expected that part of the NM80 rotor plane inflow sometimes could be affected by wakes generated from one of the two adjacent wind turbines in the wind park.

The spinner lidar-measured radial wind speed time series at $57 \mathrm{~m}$ height ( $2 \mathrm{~m}$ below hub height) in the left part of the scan $\left(102^{\circ}\right.$ azimuth angle $)$ and in the right part of the circle scan $\left(258^{\circ}\right.$ azimuth angle $)$ are presented in Figure 16 . Notice that the left and right rotor plane measured wind speeds are radial projected wind speeds and as such they must be multiplied by the factor $1 / \cos \left(30^{\circ}\right)=1.15$, that is increased by $15 \%$ before an inter comparison in magnitude with the met mast measured speeds can be done.

During the first $2000 \mathrm{~s}$, the time series obtained from the left and the right side of the rotor plane, respectively, exhibit relatively similar wind speed patterns, representative of homogeneous inflow in the rotor plane. However, later on (between 2100 and 2300 s), a significantly larger deviation between the measurements from the left and the right sides of the rotor

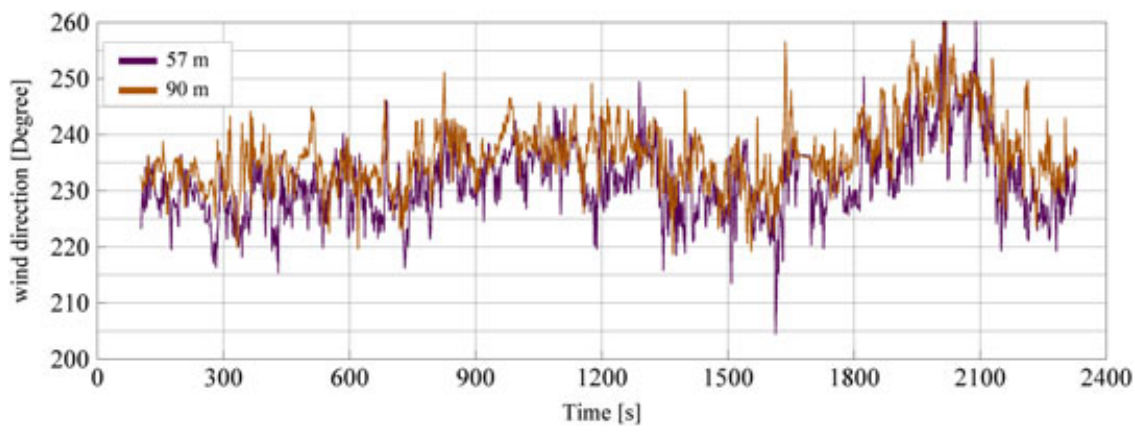

Figure 14. Wind direction at 57 and $90 \mathrm{~m}$ measured by two wind vanes installed at the met mast. 


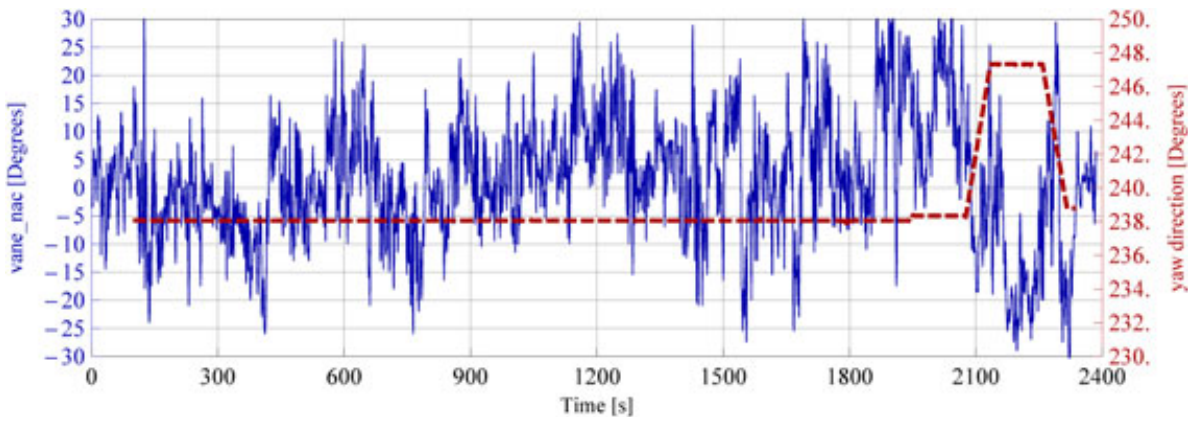

Figure 15. Yaw direction of the wind turbine and yaw misalignment (measured by the wind vane on the wind turbine nacelle).

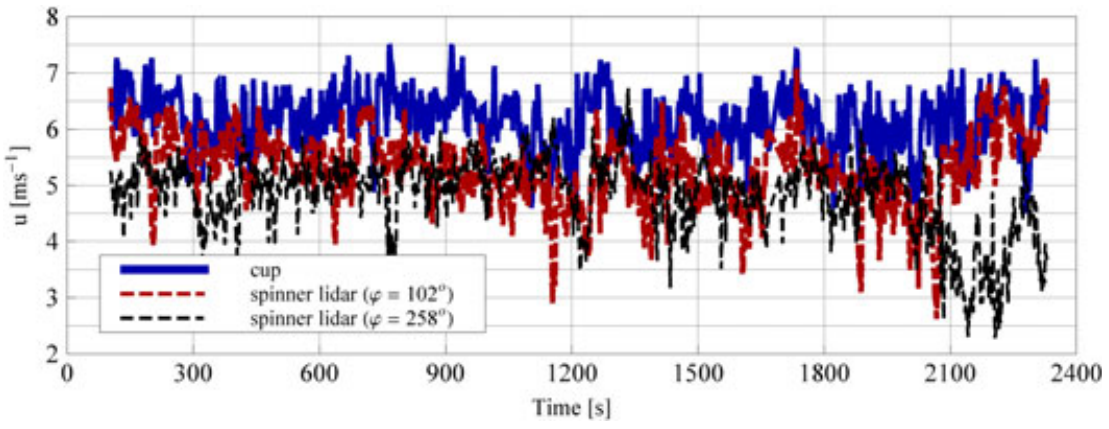

Figure 16. Radial wind speed measurements measured by the spinner lidar at $57 \mathrm{~m}$ height at the two scanner azimuth angles $\left(\varphi=102^{\circ}\right.$ and $\left.258^{\circ}\right)$. The two azimuth lidar measurements are here presented together with cup anemometer measurements from the met mast at the height level of $57 \mathrm{~m}$. Before intercomparison in speed levels, the lidars projected measurements must be corrected for a $30^{\circ}$ line-of-sight projection by multiplication with a factor of 1.15 .

plane is observed. The test wind turbine inflow is presumably affected by a wake in its right part of the rotor plane (seen from the spinner) at this instance in time, originating from wind turbine 5 ( $c f$. Figure 3 ), when the turbines inflow direction turns beyond $245^{\circ}$.

The radial wind speed measurements of the spinner lidar (not corrected for the line-of-sight projection) obtained during the period between 13:03 and 13:07 (between 2040 and 2200 s) are shown in four polar plots in Figure 17. Each 1 min polar plot contains 70 consecutive scans (approximately $0.85 \mathrm{~s}$ are required to complete a full $2 \pi$ scan in the upwind rotor plane with the actual sub-rated rotor speed). It is observed that during the first $2 \mathrm{~min}$, the radial wind speeds are circular symmetric around the turbine axis, whereas during the last $2 \mathrm{~min}$, this is no longer the case. Higher wind speeds are measured in the right half of the inflow (azimuth $0^{\circ}-180^{\circ}$ ) compared with the left half plane $\left(180^{\circ}-360^{\circ}\right)$. This is attributed to yaw misalignment during the last $2 \mathrm{~min}$. As the last two of the four figures show, yaw misalignment result in easily detectable differences in the line-of-sight wind speed measurements.

Figure 18 presents the spinner lidar-measured yaw scatter as function of variable averaging time during the analyzed unstable measurement period.

The turbine-mounted spinner lidar estimated yaw misalignment excursion errors appeared to be larger than for the ones retrieved from the wind vanes. One cause could be the uncertainty of wind lidar measurements caused by the 'Cyclops syndrome' errors (i.e. cross-wind component contamination), although these are likely to be smaller here with the $30^{\circ}$ scanning wedge combined with shorter range. Another possible cause is the influence of wakes produced by the adjacent turbines when the wind has a direction close to $250^{\circ}$.

Finally, as can also be observed in Figure 19, the spinner lidar was able to detect the wind direction changes 10-20 s prior to the wind vane on the nacelle of the wind turbine. This information potentially could be used as an additional input for improving the yaw performance on the basis of lidar-based preview for wind turbines.

\subsection{Lidar-measured power curves}

Power curves based on previewed spinner lidar wind measurements were performed with the measurements on 30 April 2009 obtained during stable stratified atmospheric inflow conditions. 

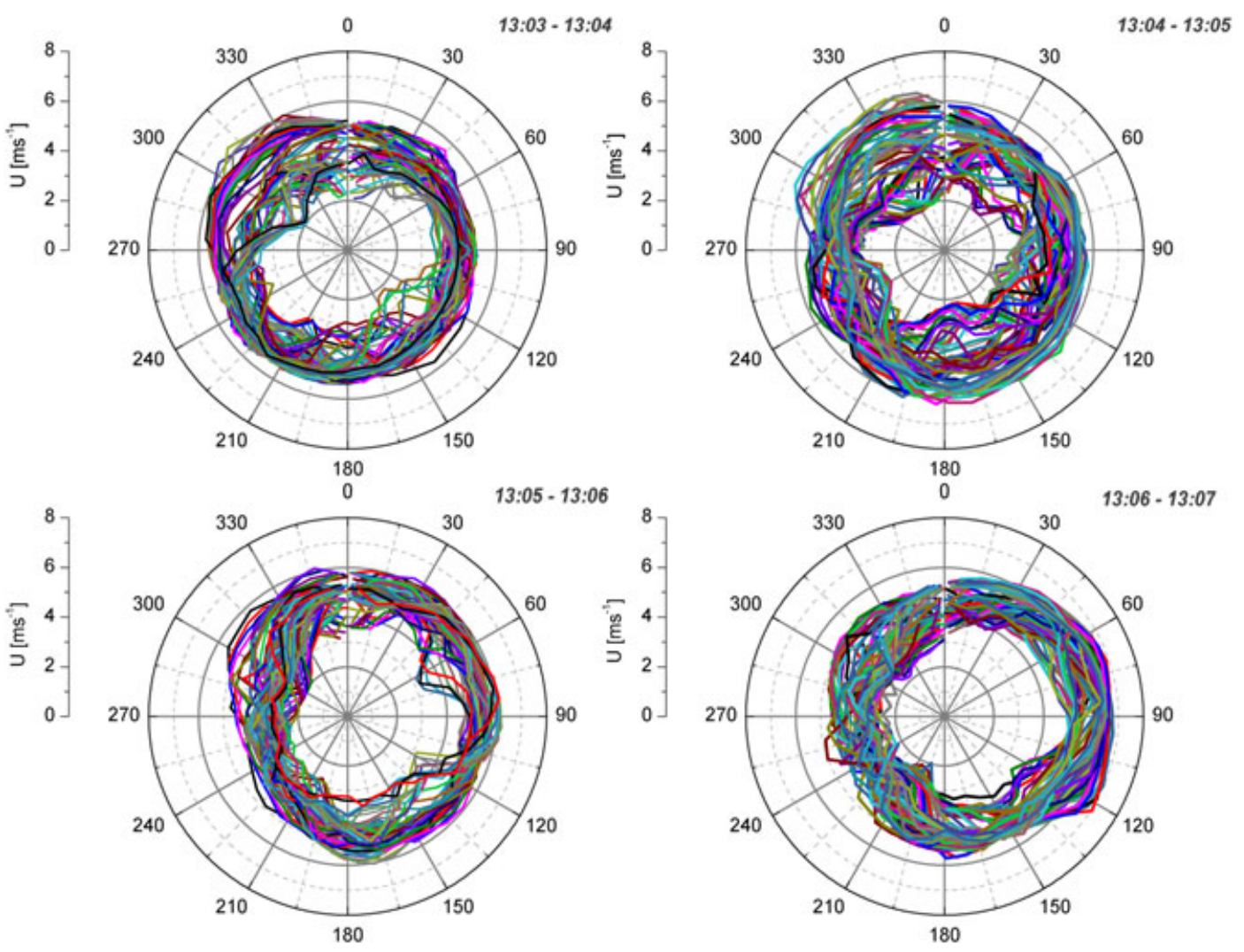

Figure 17. Polar plots (view toward wind turbine) of the radial wind speed measurements by the spinner lidar from a distance of $45.9 \mathrm{~m} ; 0.57 \varnothing$ in front of the wind turbine rotor during unstable unstratified daytime inflow during four consecutive minutes of sampling at noon on 16 July 2009.

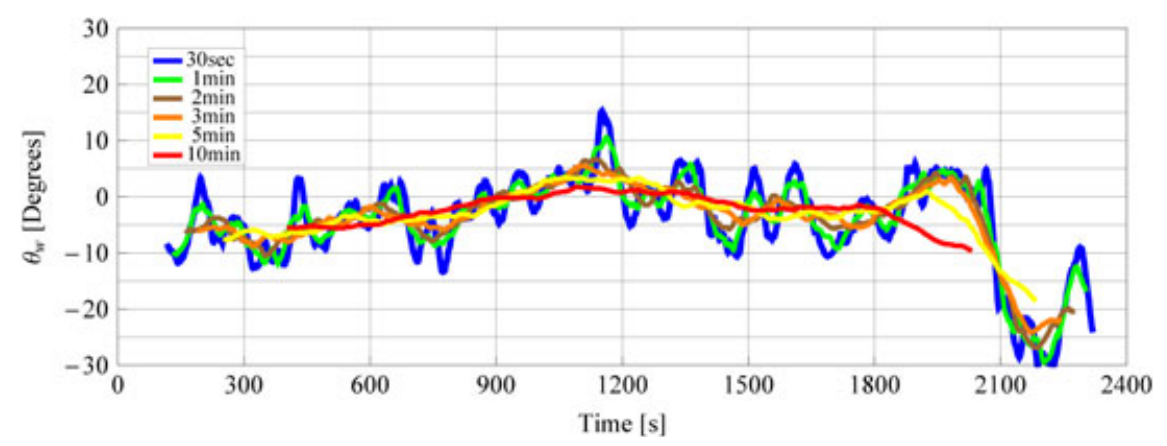

Figure 18. Yaw misalignment $\theta_{\mathrm{w}}$ of the NM80 wind turbine relative to the spinner lidar measured wind direction in the rotor plane $45.9 \mathrm{~m} ; 0.57 \varnothing$ upwind. Six different running averaging times have been supplied to the $1.25 \mathrm{~Hz}$ sampled yaw measurements (30 s, 1, 2, 3, 5 and $10 \mathrm{~min})$.

Only inflow from unobstructed and wake-free wind directions has been included in the analysis. The rotor plane-projected wind speed measurements were obtained from subsets of the spinner lidar's azimuth scans limited to height ranges within $\pm 2.5 \mathrm{~m}$ of the hub height by again using the coordinate transformation methodology described in Appendix A.

Furthermore, to fully eliminate possible wake effects from the turbines at Tjæreborg Enge to influence the met mast cup wind speed measurements, the data points contained in the power curve measurements presented in Figure 20 were furthermore filtered to include only periods where the wind direction was in the range $20-30^{\circ}$ (NNE).

The spinner lidar thus provides inflow wind speed measurements for the power curve assessment from $99.5 \mathrm{~m}(1.24 \varnothing)$ upwind distance as did wind speed measurements from the near-hub height-mounted cup anemometer mounted on the adjacent met mast (Figure 20). 


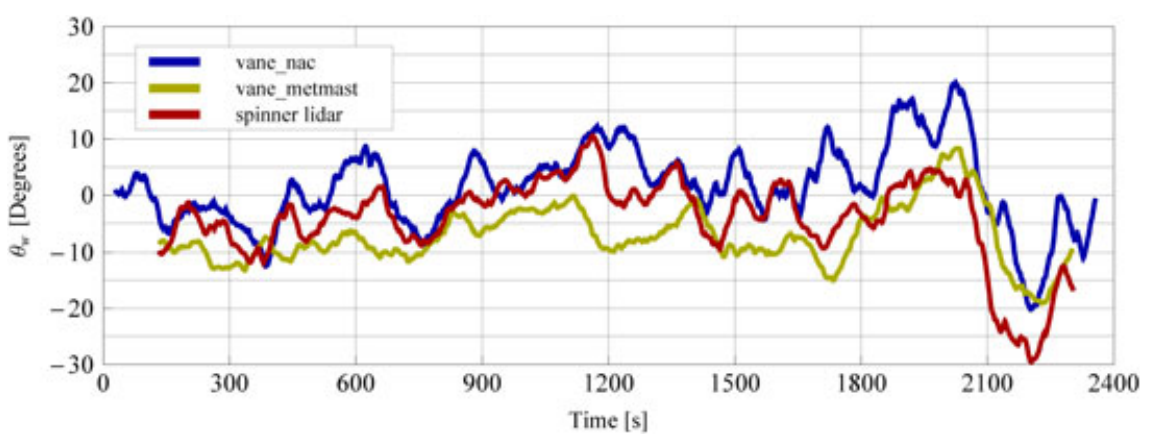

Figure 19. Yaw misalignment relative to the 1 min moving averaged mean wind direction measured by (1) the wind turbines nacellemounted wind vane behind the rotor, (2) the wind vane mounted at hub height in the $310 \mathrm{~m}$ upwind met mast and (3) the $+45.9 \mathrm{~m}$;

0.56 ø upwind-looking spinner lidar.
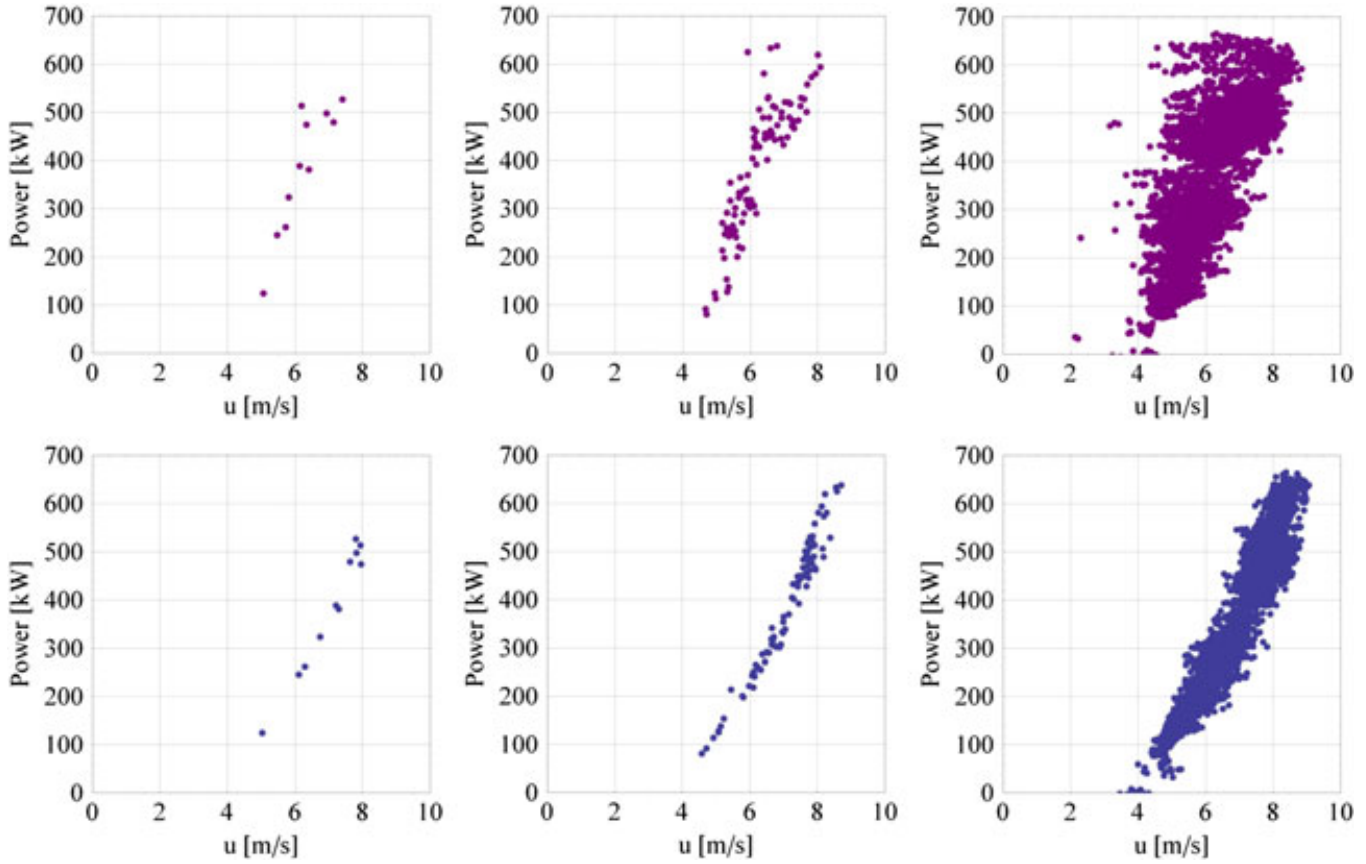

Figure 20. (Upper panel) Power curves based on hub height cup anemometer compared with (lower panel) simultaneous measured power curves based on spinner lidar-measured inflow at $99.5 \mathrm{~m}$; 1.24 ø upwind. Measured power curves are shown for $10 \mathrm{~min}$ (left), $1 \mathrm{~min}$ (middle) and $1 \mathrm{~s}$ (right) averages.

The scatter in the power curves increases, as expected, with decreasing averaging time. Furthermore, the spinner lidar-based power curves exhibited less scatter relative to simultaneously measured cup anemometer-based power curves, particular for the very short time $1 \mathrm{~s}$ averaged wind data shown.

We believe that this enhanced correlation between lidar wind and turbine power, even on the short timescale, is a result of the lidar's more representative measurement of the rotor averaged wind speed. This is a result of the combination of the effective low-pass filtering caused by the lidar's elongated sampling volume $(26 \mathrm{~m})$ relative to the cup anemometer's length scale $(1.6 \mathrm{~m})$.

Furthermore, increased scatter in the cup anemometer can be expected in short time average data because of the frequent small angular misalignment of the met mast with the wind turbine as opposed to the lidar measurements, which are always aligned to the turbine's rotor disk.

Further decreased scatter in the spinner lidar-based power curve assessments might be achieved by adaptation of more comprehensive wind speed and wind direction data extraction models, for example, by fitting to scanned lidar inflow over full cone scans or even over full two-dimensional rotor plane filling inflow scans. Models adapted to full circular inflow and also to full two-dimensional rotor plane upwind inflow wind scanner measurements are now under development and testing. 


\section{DISCUSSIONS AND OUTLOOK}

During operation, the control system on a turbine adjusts several parameters including (1) the turbine's yaw into the mean wind direction, (2) the blade pitch angles collectively or individually and (3) the speed of the rotor, in order to optimize energy production and to minimize the loads from the wind gusts and wind shear.

The control subsystems are operating on different timescales. A typical yaw control strategy is to monitor the average yaw error during a period, e.g. $10 \mathrm{~min}$, and then activate yawing if a preset yaw error limit has been exceeded, whereas pitch controllers set the angle of attack of the blades on a sub-second timescale on individual pitch and on a second-long timescale on collective pitch.

The previewing spinner lidar has been demonstrated to be capable of providing two types of information:

1. $2 \mathrm{D}$ inflow wind field information: The spinner lidar with its embedded $2 \pi$ per second rotating prism scanner provides 50 wind speed measurements per second of upwind circular-scanned radially projected inflow. Since the turbine spinner itself during rated power operation rotates at an angular speed of about $1.81 \mathrm{rad} \mathrm{s}^{-1}$, in the same direction as the prism scanner of the spinner lidar rotates its laser beam, approximately 40 measurement points are distributed evenly on each completed full $2 \pi$ circle scan every $0.8 \mathrm{~s}$. The spinner lidar rotor plane circular-scanned wind measurements, including wind shear and wind veer, have revealed substantial variations in the rotor plane inflow that could not have been detected by a single-point hub height wind measurement from a nearby met mast nor from nacelle or rotor front spinner-integrated anemometer. ${ }^{22}$

2. Prevision for feed-forward control: Upwind remote measurements of inflow from a wind turbine-integrated wind lidar can also provide prevision for feed forward-based control. From integrating wind lidars in the spinner or in the blades, wind speed including even 2D wind vector inflow can today be operationally measured upwind in the rotor plane to provide preview and hence valuable information for the controllers of both static and also existing approaching wind gusts and wind shear with a lead time of up to, say 5-10 s.

Wind lidars integrated in wind turbines have resulted in an increased interest in research and demonstration activities that together with recent advances in wind turbine control holds potential for improvements of wind turbine performance via optimization of yaw, pitch and speed control, with the objective to enhance power and to reduce extreme and fatigue loads.

The spinner lidar measurements presented are seen to compare well with the conventional nacelle-mounted instruments, apart from some jitter, so why not just use the nacelle mounted instruments? What extra benefit accrues from using the spinner lidar?

We believe that there are two potential benefits of lidar-assisted control and these are (1) entire rotor plane wind field inflow measurements which contain information of shear and veer and such information is not available, not even from an optimal yaw strategy based on the existing nacelle or spinner anemometer mounted instruments and (2) the effects of preview.

Preview can assist yaw, pitch and speed control $\left(c f\right.$. the recent simulation works referenced in Section $\left.1^{8-17}\right)$. Obviously, judging from the referenced simulation studies, there is substantial evidence that preview holds potential for mitigating loads and also for enhancing, although to a lesser degree, the power.

Regarding yaw control, however, it has been questioned whether lidar preview will be able to provide much better wind direction information than ideal and flow disturbance-corrected wind direction measurements from instruments mounted on the nacelle behind the rotor, or alternatively, from a precision spinner anemometer mounted in the spinner in front of the rotor plane.

Nevertheless, depending on the implemented yaw control strategy, there will still be potential benefits from previewbased yaw control, because lidar preview of inflow direction can provide the yaw controller with some lead time, depending on set previewed distance, of the order of 10-20 s, to dynamically yaw the turbine up into the wind faster than a nacelle anemometer and wind vane can do by 'driving the turbine by looking in the rear mirror'.

A simple estimate of sub-optimal power production due to yaw misalignment can be derived from Betz's power law:

$$
P=\frac{1}{2} C_{\mathrm{p}} A \rho U^{3}
$$

Here, $P$ is the wind turbine power, $C_{\mathrm{p}}$ is the power coefficient, $A$ is the effective swept rotor area and $U$ is the wind speed at hub height.

If it is assumed, not unrealistically from the measurements presented in Table I, that $10^{\circ} \mathrm{RMS}$ yaw misalignment is typically experienced during, e.g. a $10 \mathrm{~min}$ sampling period, the power loss, estimated from a first order expansion of the mean cosine dependence of the rotor plane projected wind speed, becomes

$$
\overline{\cos \left(\theta_{\mathrm{w}}\right)} \simeq 1-{ }_{1 / 2} \overline{\theta_{\mathrm{w}}^{2}} ; \overline{\theta_{\mathrm{w}}^{2}} \simeq\left(\pi \frac{10}{180}\right)^{2}=0.0305 ; \overline{\cos \left(\theta_{\mathrm{w}}\right)}=0.9848
$$

Applying this 'cosine projection loss-factor' to the wind speed in Betz's speed-cubed power law formula, the overall power loss due to yaw misalignment, $\Delta P_{10^{\circ} \mathrm{RMS}}$, due to a $10^{\circ} \mathrm{RMS}$ yaw misalignment, can be approximately estimated as: ${ }^{16}$ 


$$
\Delta P_{10^{\circ} \mathrm{RMS}}=3\left(1 / 2 \overline{\theta_{\mathrm{w}}^{2}}\right)=3 \times 0.0152=0.0456 ;(4.6 \% \text { loss })
$$

Although the $10 \mathrm{~min}$ averaged yaw misalignment was found to remain within the interval $-1^{\circ}$ to $+20^{\circ}$ during the $3 \mathrm{~h}$ 20 min test period on 30 April 2009, the shorter-term averaged yaw errors were observed to exhibit even bigger deviations, by as much as $-20^{\circ}$ to $+40^{\circ}$. There is therefore, we believe, significant potential for improvement, depending on wind conditions and the turbine implemented yaw strategy, via optimizing wind turbines' yaw alignment procedures. These improvements, however, are not exclusively limited to prevision lidar-based yaw control. Also a less conservative turbine yaw control strategy, and based on, e.g. rotor plane front-installed spinner anemometry, should in principle be able to release this yaw misalignment power enhancement potential.

A more rigorous investigation of the potential improvements in performance from using the spinner lidar's yaw alignment potential has recently been studied by simulations, $c f$. Kragh et al. ${ }^{16}$

\subsection{The spinner lidar sounding volume effect on measured turbulence, eddy decay and coherence}

Finally, another issue connected with upwind lidar measurements of wind and turbulence relates to the spinner lidar sounding volume turbulence filtering effects and assessment of the measured coherence and eddy decay.

The low-pass filtering effects on turbulence caused by the lidar's probing volume effect have recently been investigated with the CW ZephIR lidar used in the Tjæreborg 2009 experiment. A simple analytical model for the spectral transfer function of this lidar has been proposed and evaluated experimentally. In essence, the transfer function of the lidar filters eddies of size smaller than the line-of-sight focus distance-dependent spatial resolution of the lidar. Furthermore, the transfer function depends also on the pointing direction of the laser beam relative to the mean wind direction. ${ }^{19-21}$

Investigations are still ongoing, however, aiming at assessing representativeness for coherence and decay related to upwind lidar-measured turbulence and gusts, and on the application and limitations of Taylor's frozen turbulence hypothesis. ${ }^{21,23,24}$ The $^{2}$ results will serve as the foundation for the devising of methodologies to measure incoming gusts experimentally as well as for experimental investigations of the optimal upwind distance for wind lidar measurements regarding the maximum correlation between the upwind measured gusts and turbulence and the loads they predict to exert on the rotor blades in relation to the preview lead time provided.

Empirically, we have investigated this and found that the rate of turbulence decay during transport depends on eddy size. At typical hub heights $(100 \mathrm{~m})$ measurements of coherent structures indicate that eddies of size $\lambda>4 D$, where $D$ is the preview distance, will not decay significantly but will remain 'frozen' during transport from their upwind previewed measurement point, till they hit the rotor plane. ${ }^{21,23}$ If the preview distance is $50 \mathrm{~m}$, this means that eddies or coherent structures of size $\sim 200 \mathrm{~m}$ will reach the rotor plane unchanged.

On the other hand, structures of size comparable with the dimension of the rotor, say $100 \mathrm{~m}$, can be expected to decay and change form.

Preview-based feed-forward controller design will have to take this correlation decay into account. Presently, pulsed lidar systems able to measure inflow wind speed at multiple ranges gates simultaneously are employed in investigations of coherence, i.e. decay as function of preview distance and eddy size. ${ }^{9,21,23,24}$

\subsection{The next step: upwind lidar measurements integrated with active pitch control}

When combined with the control systems of the turbine, we anticipate that spinner lidar-based measurements one day may enable real-time upwind-based control data to the turbine's individual blade pitch control (IPC) systems and in this way help compensate and mitigate the effects of yaw errors and strong wind shear and veer on the turbines equipped with upwind looking wind lidars for control.

We anticipate that previewed wind lidar measurements in combination with more proactive feed forward-based yaw control algorithms and IPC control systems can lead to enhancements in power performance, particularly during sub-rated wind regime operation. This, and also load reduction, is planned to be demonstrated in forthcoming test turbine experiments equipped with spinner-mounted upwind-looking wind lidars for providing real-time preview inflow wind data for feed-forward wind turbine control.

\section{CONCLUSIONS}

We report what we believe are the first-ever spinner-based lidar measurements of wind speeds sampled from the rotating spinner of an operating wind turbine.

The 'Tjæreborg 2009 spinner lidar experiment' has demonstrated that a contemporary CW wind lidar (ZephIR) when mounted in the turbine spinner is able to measure the upwind approaching wind and turbulence structures from scanning the wind field about the turbine axis in real time. 
The instantaneous yaw errors of a 2.3 MW test turbine have been measured during operation in real-time. It was shown that the vertical wind profiles as well as the power curves of the wind turbine can be measured on the basis the radial wind measurements from a spinner-mounted wind lidar.

The first results, based on analysis of the data from 30 April 2009 further encourage development and integration of wind lidar technologies in the area of active control and improvement of wind turbine performance.

To summarize, the main achievement is the spinner-integrated wind lidar in the Tjæreborg test turbine has shown that a wind lidar is capable of providing useful upwind measurements of

1. Mean wind speed at hub height

2. Vertical wind shear profiles

3. Wind direction and yaw misalignment

4. Power curves

5. Lead time for warning of incoming gusts and wind direction changes, with a 5-10s lead time depending on wind speed

Our tests and analysis have also provided encouragement for development of a more comprehensive rotor plane wind flow model that can fit speed, shear, direction and yaw to the entire set of radial wind speed measurements obtained by the lidar per second by its conical scanning upwind.

The next stages of development involve further wind lidar integration experiments and further data analysis including modeling and simulations of spinner lidar data as input to the wind turbines' yaw and pitch control systems, toward quantitative assessment of the potential for turbine performance improvement.

\section{ACKNOWLEDGEMENTS}

Michael Rasmussen and Per Hansen of Ris $\varnothing$ DTU and Dong Energy are gratefully acknowledged for skilled technical support and for access to the NM80 test turbine at Tjæreborg. Vestas Wind Systems is acknowledged for safe operations of the NM80 turbine. Access to Dong Energy's NM80 Tjæreborg wind turbine and the local met mast data has been facilitated in collaboration with the simultaneously ongoing DAN-AERO and TOPFARM test activities and is also gratefully appreciated. Meteorology and turbine data were provided by the DAN-AERO MW project, carried out by Vestas, Siemens, LM, DONG Energy and Risø DTU in cooperation and funded partly by EFP-2007, 'Experimental Rotor- and Airfoil Aerodynamics on MW Wind Turbines' contract no. 33033-0074 and partly by the participants. The Tjæreborg NM80 spinner lidar experiment has been conducted as part of the new Danish research infrastructure facility activities under the auspices of WindScanner.dk Danish Agency for Science, Technology and Innovation, Research Infrastructure 2009 Grant No. 2136-080022. Post-analysis of results was performed during 2010 with support from the Danish Advanced Technology Foundation: Grant 049-2009-3: Integration of Wind LIDAR's In Wind Turbines for Improved Productivity and Control.

\section{APPENDIX A}

Figure A1 Spinner lidar measurement lidar geometry

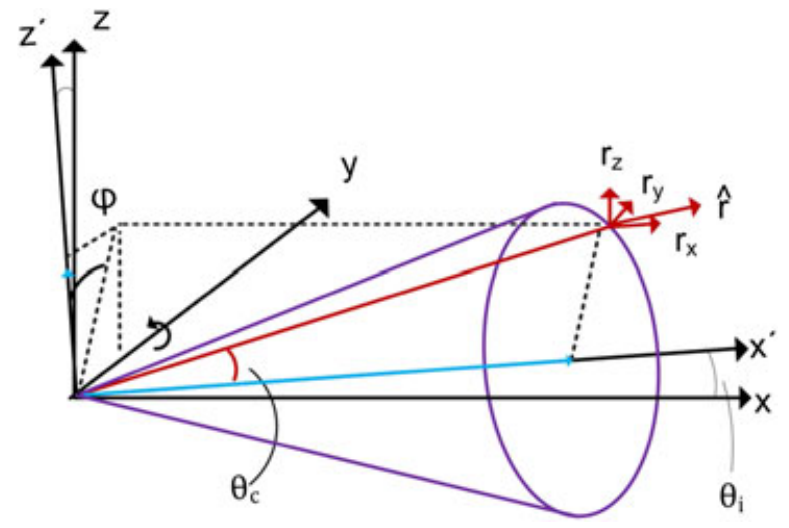

The spinner lidar acquired radial wind speed measurements by conical scanning around the wind turbine's axis of rotation, which in the horizontal plane is steered by the wind turbine yaw control and the vertical direction is elevated in a fixed angle, $\theta_{i}\left(5^{\circ}\right.$ for the NM80 wind turbine). 
The lidar measures the wind speed projected along the lidar's instantaneous line-of-sight unit pointing vector, here denoted by $\hat{r}$, and is given by

$$
\hat{r}=\left(r_{x}, r_{y}, r_{z}\right)=\left(\cos \theta_{\mathrm{C}}, \sin \theta_{\mathrm{C}} \sin \varphi, \sin \theta_{\mathrm{C}} \cos \varphi\right)
$$

where the lidar's fixed off-turbine axis deflection angle is denoted $\theta_{C}\left(15^{\circ}\right.$ or $30^{\circ}$ in this study $)$ and the azimuth angle caused by rotation of the lidar's prism is denoted $\varphi$.

In this tilted and yawed coordinate system, the measured wind speed is

$$
U_{\text {lidar }}=\hat{r} \cdot \mathbf{u}=\left(r_{x}, r_{y}, r_{z}\right) \cdot\left(u_{x}, u_{y}, u_{z}\right)
$$

where $\left(u_{x}, u_{y}, u_{z}\right)$ are the wind components of the instantaneous wind vector in the frame of reference attached to the ground. We assume that the mean wind direction is along the $x$-axis.

To relate the line-of-sight pointing vector $\hat{r}$ in the tilted and yawed reference system to the fixed frame of reference for the wind vector, we first had to apply the following two coordinate rotations:

i Relative to a fixed coordinate system attached to the ground $(x, y, z)$, the vertical tilt of the wind turbine axis is represented by a counter-clockwise rotation about the $y$-axis:

$$
\left[\begin{array}{l}
x^{\prime} \\
y^{\prime} \\
z^{\prime}
\end{array}\right]=\left[\begin{array}{ccc}
\cos \theta_{i} & 0 & -\sin \theta \\
0 & 1 & 0 \\
\sin \theta_{i} & 0 & \cos \theta_{i}
\end{array}\right]\left[\begin{array}{l}
x \\
y \\
z
\end{array}\right]
$$

ii Similarly, the instantaneous yaw misalignment of the wind turbine, $\theta_{\mathrm{W}}$, relative to the $x$-axis is taken into account by rotation around the $z$-axis, viz.

$$
\left[\begin{array}{l}
x^{\prime \prime} \\
y^{\prime \prime} \\
z^{\prime \prime}
\end{array}\right]=\left[\begin{array}{ccc}
\cos \theta_{\mathrm{w}} & -\sin \theta_{\mathrm{w}} & 0 \\
\sin \theta_{\mathrm{w}} & \cos \theta_{\mathrm{w}} & 0 \\
0 & 0 & 1
\end{array}\right]\left[\begin{array}{l}
x^{\prime} \\
y^{\prime} \\
z^{\prime}
\end{array}\right]
$$

From (A3) and (A4), an expression for the lidar's instantaneous radial wind speed is derived by relating the pointing vector $\hat{r}$ in (A1) to the fixed frame as function of tilt, azimuth, wedge deflection angle and yaw angle.

\section{REFERENCES}

1. Karlsson CJ, Olsson FÅA, Letalick D, Harris M. All-fiber multifunction continuous-wave coherent laser radar at $1.55 \mu \mathrm{m}$ for range, speed, vibration and wind measurements. Applied Optics 2000; 39: 3716-3726. DOI: 10.1364/ AO.39.003716

2. Harris M, Hand M, Wright A. A lidar for turbine control. Tech. Rep. NREL/TP-500-39154 National Renewable Energy, National Renewable Energy Laboratory, NREL, Golden, Colorado, US, (2006).

3. Smith DA, Harris M, Coffey AS, Mikkelsen T, Jørgensen HE, Mann J, Danielian R. Wind lidar evaluation at the Danish wind test site in Høvsøre, Wind Energy 2006: 9: 87-93. DOI: 10.1002/we.193

4. Harris M, Bryce DJ, Coffey AS, Smith DA, Birkemeyer J, Knopf U. Advance measurement of gusts by laser anemometry. Wind Engineering and Industrial Aerodynamics 2007: 95: 1637-1647. DOI: 10.1016/j.jweia.2007.02.029

5. Mikkelsen T. On mean wind and turbulence profile measurements from ground-based wind lidar's: limitations in time and space resolution with continuous wave and pulsed lidar systems-a review. Presented at 2009 European Wind Energy Conference and Exhibition. Marseille (France), 16-19 Mar, 2009. In EWEC 2009 Proceedings (online): Wind Profiles at Great Heights, 10 pages plus poster P.O. 171. EWEC, 2009.

6. Mikkelsen T, Hansen KH, Angelou N, Sjöholm M, Harris M, Hadley P, Scullion R, Ellis G, Vives G. Lidar wind speed measurements from a rotating spinner. In: EWEC 2010 Online Proceedings, 2010 European Wind Energy Conference and Exhibition, 2010, Warsaw, Poland, 20-23 Apr, 2010; 8pp.

7. Sjöholm M, Mikkelsen T, Mann J, Enevoldsen K, Courtney M. Spatial averaging-effects on turbulence measured by a continuous-wave coherent lidar. Meteorologische Zeitschrift 2009; 18: 281-287. DOI: 10.1127/0941-2948/2009/0379

8. Schlipf D, Kuhn M. Prospects of a collective pitch control by means of predictive disturbance compensation assisted by wind speed measurements. German Wind Energy Conference (DEWEK), Bremen, Germany, 2008; 1-4. 
9. Schlipf D, Schuler S, Grau P, Allgower F, Kuhn M. Look-ahead cyclic pitch control using lidar. TORQUE 2010, Third Conference, Greece, 28-30 June 2010; 1-7.

10. Simley E, Pao LY, Frehlich R, Jonkman B, Kelley N. Analysis of wind speed measurements using continuous wave lidar for wind turbine control. Proceedings of 49th AIAA Aerospace Sciences Meeting including the New Horizons Forum and Aerospace Exposition. American Institute of Aeronautics and Astronautics, AIAA, Orlando, Florida, 4-7 January 2011; 2011-263.

11. Dunne F, Pao LY, Wright AD, Jonkman B, Kelley N, Simley E. Adding feed-forward blade pitch control for load mitigation in wind turbines: non-causal series expansion, preview control, and optimized FIR filter methods. Proceedings of 49th AIAA Aerospace Sciences Meeting including the New Horizons Forum and Aerospace Exposition. American Institute of Aeronautics and Astronautics, AIAA, Orlando, Florida, 4-7 January 2011; 2011-819.

12. Laks J, Pao LY, Simley E, Wright A, Kelley N, Jonkman B. Model predictive control using preview measurements from lidar. Proceedings of 49th AIAA Aerospace Sciences Meeting including the New Horizons Forum and Aerospace Exposition. American Institute of Aeronautics and Astronautics, AIAA, Orlando, Florida, 4-7 January 2011; 2011-813.

13. Kragh KA, Hansen MH. Individual pitch control based on local and upstream inflow measurements. Proceedings of 49th AIAA Aerospace Sciences Meeting including the New Horizons Forum and Aerospace Exposition, American Institute of Aeronautics and Astronautics, AIAA, Orlando, Florida, 4-7 January 2011; 2011-813.

14. Kragh KA, Fleming PA. Rotor speed dependent yaw control of wind turbines based on empirical data. Proceedings of 50th AIAA Aerospace Sciences Meetings and Exhibit, American Institute of Aeronautics and Astronautics, Nashville, Tennessee, USA, 9-12 Jan 2012.

15. Kragh KA, Hansen MH, Mikkelsen T. Improving yaw alignment using spinner based lidar. Proceedings of 49th AIAA, Aerospace Sciences Meeting Including the New Horizons Forum and Aerospace Exposition, American Institute of Aeronautics and Astronautics, AIAA: Orlando, USA, FL, 4-7 Jan 2011.

16. Kragh KA, Hansen MH, Mikkelsen T. Precision and shortcomings of yaw error estimation using spinner-based light detection and ranging. Wind Energy 2012. DOI: 10.1002/we.1492.

17. Schlipf D, Anger J, Kapp S, Bischoff O, Hofsäß M, Rettenmeier A, Kühn M. Prospects of optimization of energy production by lidar assisted control of wind turbines. Proceedings of European Wind Energy Conference and Exhibition, EWEA, Brussels (B), 14-17 March 2011.

18. Angelou N, Mikkelsen T, Hansen KH, Sjöholm M, Harris M. LIDAR wind speed measurements from a rotating spinner: 'SpinnerEx 2009', Ris $\varnothing-R-1741(E N)$, Ris $\varnothing$ DTU, August 2010, ISBN 978-87-550-3836-3, 79 p.

19. Angelou N, Mann J, Sjöholm M, Courtney M. Direct measurement of the spectral transfer function of a laser based anemometer. The Review of Scientific Instruments 2012; 83: 033111. DOI: 10.1063/1.3697728.

20. Sjöholm M, Mikkelsen T, Kristensen L, Mann J, Kirkegaard P, Kapp S, Schlipf D, Trujillo JJ. Spectral analysis of wind turbulence measured by a Doppler Lidar for velocity fine structure and coherence studies. Online Proceedings from International Symposium for the Advancement of Boundary Layer Remote Sensing, P-MEA/19, ISARS 2010, Paris, FR, 28-30 June 2010.

21. Sjöholm M, Mikkelsen T, Kristensen L, Kapp S. Experimental evaluation of a model for the influence of coherent wind lidars on their remote measurements of atmospheric boundary-layer turbulence. International Society for Optical Engineering 2011; 8182. DOI: 10.1117/12.897918.

22. Pedersen TF, Gottschall J, Frandsen ST, Runge Kristoffersen J, Dahlberg JA, Christiansen W, Weich G, Ormell F. Application of spinner anemometry in yaw alignment control. Proceedings of EWEC 2010 European Wind Energy Conference and Exhibition, Warsaw, Poland, 20-23 Apr. 2010.

23. Schlipf D, Trabucchi D, Bischoff O, Hofsäß M, Mann J, Mikkelsen T, Rettenmeier A, Trujillo JJ, Kühn M. Testing of frozen turbulence hypothesis for wind turbine applications with a scanning lidar system, ISARS, Paris, June 2010.

24. Kristensen L, Kirkegaard P, Mann J, Mikkelsen T, Nielsen M, Sjöholm M. Spectral coherence along a lidar-anemometer beam. Ris $\varnothing-R-1744(E N)$, Risø DTU. October 2010, ISBN 978-87-550-3840-0, 20 p. 